Portland State University

PDXScholar

\title{
A Politically Appointed Task Force: Can It be
} Effective?

Randolph Latourette Miller

Portland State University

Follow this and additional works at: https://pdxscholar.library.pdx.edu/open_access_etds

Part of the Political Science Commons Let us know how access to this document benefits you.

Recommended Citation

Miller, Randolph Latourette, "A Politically Appointed Task Force: Can It be Effective?" (1977). Dissertations and Theses. Paper 2600.

https://doi.org/10.15760/etd.2596

This Thesis is brought to you for free and open access. It has been accepted for inclusion in Dissertations and Theses by an authorized administrator of PDXScholar. Please contact us if we can make this document more accessible: pdxscholar@pdx.edu. 
AN ABSTRACT OF THE THESIS OF RandoIph Latourette Milier for the Master of Science in Political Science presented July, 1977.

Title: A Politically Appointed Task Force: Can It Be Effective?

APPROVED BY MEMBERS OF THE THESIS CONMITTEE:

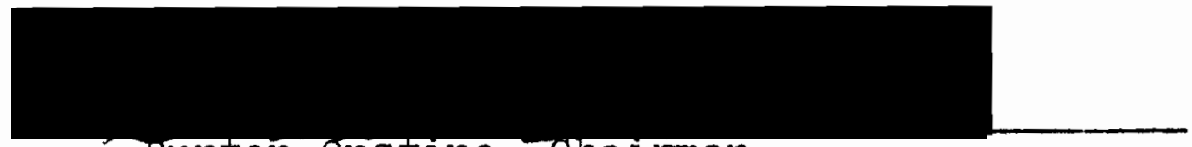
Burton onstine, Chairman
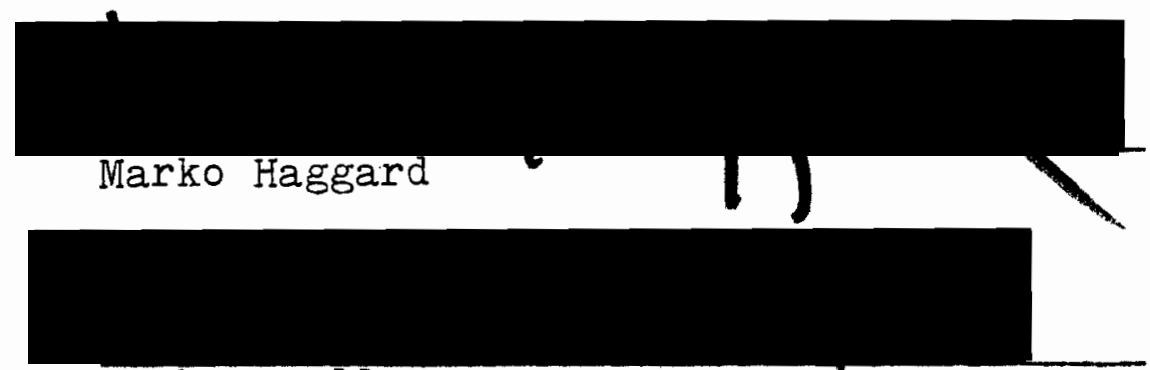
Hugh LoveII

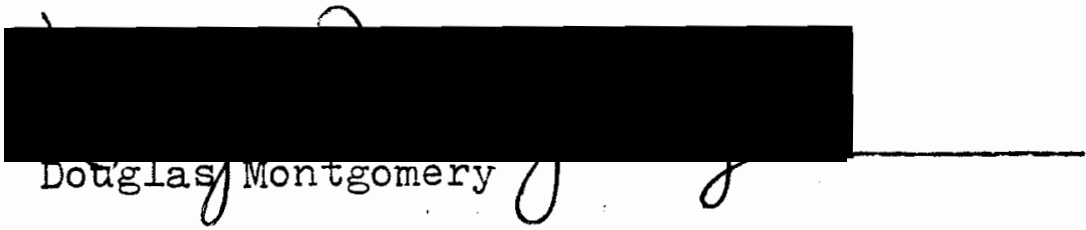

Community service projects have consistently been an effective mears of community involvement and an avenue in which improvement in an area may be measured. Although the roles each participant assumes may differ, the ultimate accomplishment of the project is paramount to each person involved.

This paper will explore the Governor's Task Force 
on Venereal Disease to determine both the effectiveness of the Task Force and the methods utilized to accomplish the task force goals. Primarily, this group of selected individuals will be reviewed to determine whether they were effective due to their ability to influence others, or simply through a great deal of hard work and co-operation.

Data for this work was collected from individual written responses from Task Force participants, the Governor's Commission on Youth, various medical professionals, several works of other authors (see bibliography), data gathered by me as participant-observer, and through interviews from selected Task Force participants.

Upon compiling the data, several concepts were revealed. I found that the influence that each. participant enjoyed in the community was a primary factor of the effectiveness of the Task Force. Moreover, it was the influence of the particular individual with others who could assist with this particular problem which created a positive response, and thus effective results.

This paper also explores the Task Force as a politically appointed group chosen to complete a specific project. The goals, operations, and accomplishments are detailed in an effort to measure the significance of the Task Force in the community. 
A POIITICAIIY APPOINTED MASK FORCE:

CAIN IT BE EFFECTIVE?

BY

RANDOIPH IATOURETIE MILIEP

A THESIS SUBMIMTED IN PARTIAI FULFILIMENT OF TIEE REQUIRENENTS FOR THE DEGREE OF

\author{
MIASTER OF SCIENCE \\ IN \\ POIITICAI SCIENCE
}


TO THE OFFICE OF GRADUATE STUDIES AND RESEARCH:

The members of the Committee approve the thesis of Randolph Iatourette Miller presented July, 1977.

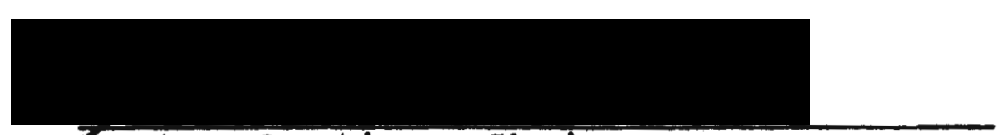

Burton Onstine, Chairman
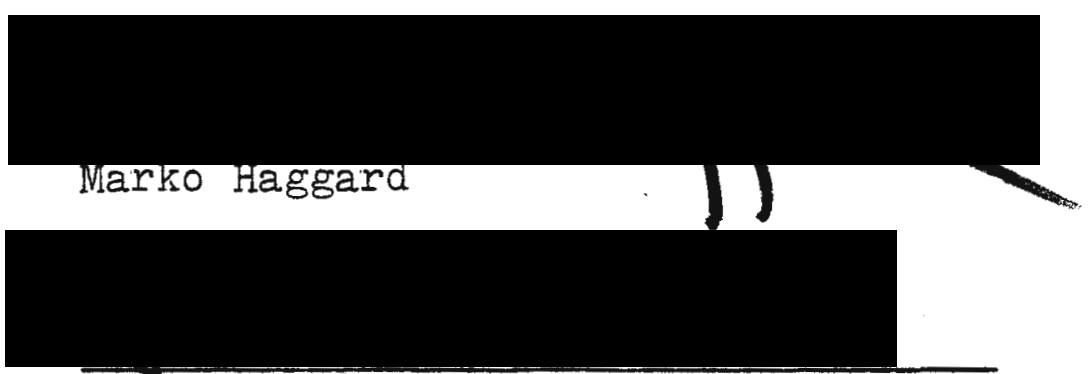

Hugh Lovell

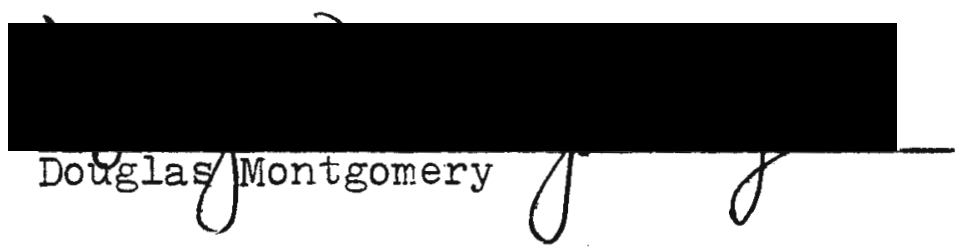

APPROVED:

Norman N. Greene, Head, Department of Political Science

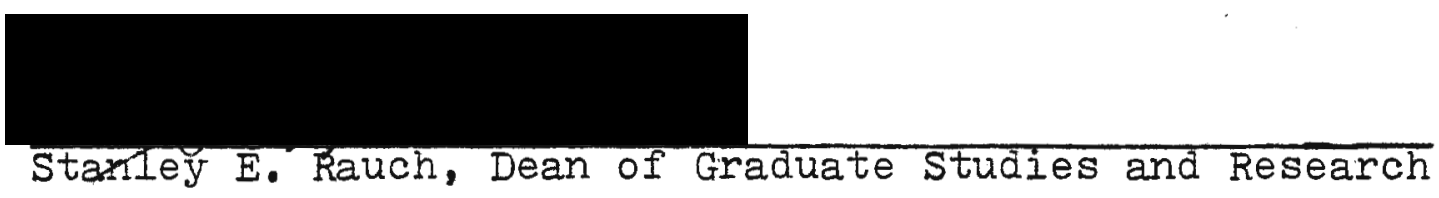




\section{ACKNOWLEDGMENTS}

This work is a result of perseverance not only by me, but also by three other particular individuals as well. I want to express my most sincere gratitude to my wife Janet, to my cousin Wendy, and to my Aunt Barbara for their devotion to me and this project. Without their support, this paper would still be a dream. 


\section{TABIE OF CONTENTS}

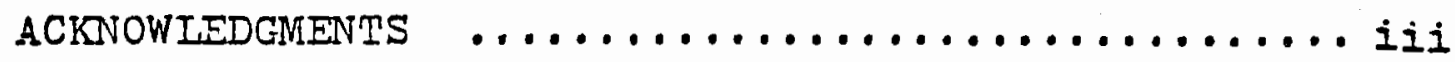
IIST OF IIIUSTRATIONS AND TABIES .............. v FOREWARD $\ldots \ldots \ldots \ldots \ldots \ldots \ldots \ldots \ldots \ldots \ldots \ldots \ldots \ldots \ldots \ldots \ldots$ Part

INTRODUCTION $\ldots \ldots \ldots \ldots \ldots \ldots \ldots \ldots$

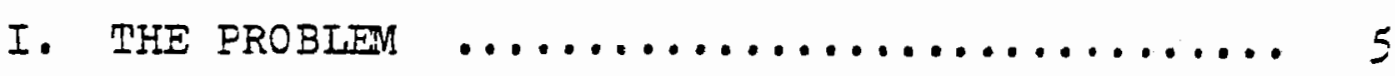

II. ADDRESSING THE PROBIEM ................ 20

III, ATTACKING THE PROBIEM ............... 34

IV . OVERCOMING THE PROBIEM ................ 56

V. EVALUATION ......................... 6 ?

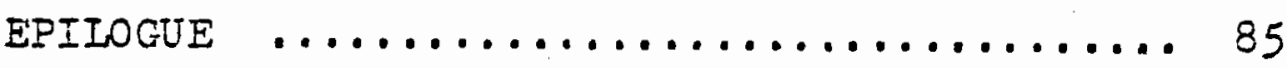

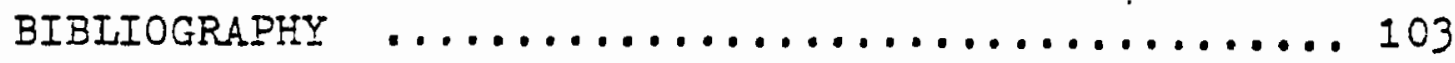

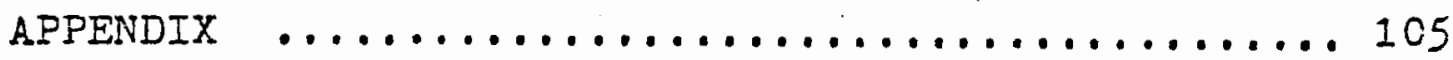


IIST OF IILUSTRATIONS AND TABIES

Questionnaire

87

Graphs and Charts

Gonorrhea: Reported cases in the United. States, 1950-1973

Primary and Secondary Syphilis: Reported cases in the United States, 1950-1973 ... 90

Communicable Diseases-Number of Reported Cases, 1972

Gonorrhea: Incidence rates per 100,000 population, 1950-1972

Syphilis: Incidence rates per 100,000 population, 1950-1972

Gonorrhea: Case rates per 100,000 potulatior. United States, 1973

Syphilis and Gonorrhea Case rates in Oregor, $1940-1973$

Tables

Gonorrhea: Case rates per 100,000 popula-

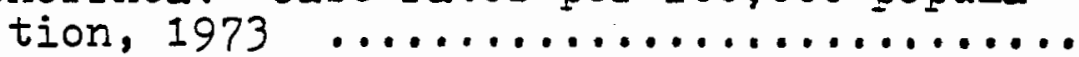
Gonorrhea: Case rates per 100,000 population, 1972, 15-19 Year Age Group and

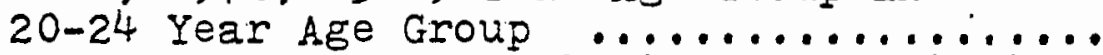
Ore gon Reported Venereal Disease Statistics,

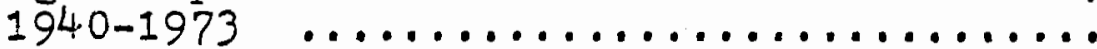

Orezon Reported Venereal Disease Statistics

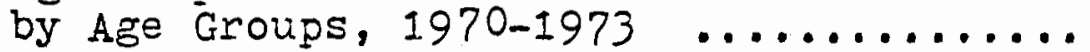

oregon Total Reported Gonorrhea Cases and Rates by County, 1973 ............... Oregon Reported Gonorrhea Cases by Specific

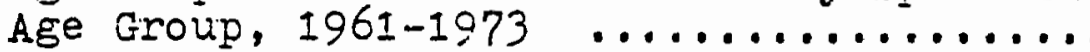
Source of Venereal Disease Case Reports, 1973

96

97

98

99

100

101

102 


\section{FOREWARD}

The following study represents an account of a politically appointed group of citizens chosen to accomplish specific goals. The goals themselves were basically established by the members once the group initiated the project, but the overall problem to be solved was to stof the ever-rising incidence of venereal disease.

The group was tagged the Governor's Venereal Disease Task Force and during the two year course of its existence, interesting characteristics began developing. Consequently, the interactions between the task force members within themselves and with the community as a whole promoted this study .

The politics of group inter-relationships depend greatly upon the purpose of the group. The following study depicts these inter-relationships and how they might be utilized towards cverall effectiveness. 


\section{INTRODUCTION}

Power structure. Influence. Hegemony. These three terms could have more significance than any other terms in community decision-making today. They provide the basis for which decisions are originated, determined, relayed and followed. They provide the basis for a line of communication between those whom govern and those whom are governed. They provide the basis for which some have definite social and economic functions that others do not.

The characteristics of power and influence vary. Influence can mean solely social or economic or political power. Conversely, it can mean the combination of all three. It can be a dual relationship between governmental and economic authorities on a national, state, or local level. Wealth, social status, and prestige can all be factors; however, it is not necessary to have all three extant to be in an influential position. There must be some structure such as an association, clique, or some institutional pattern but the significance of each orgarization can vary place to place.

Actual forms of power and influential behavior in the community can determine the effectiveness of leader- 
ship, progress, and community improvement projects. The latter of these three topics, which will be the concentration of this paper, has consistently been an effective means of community involvemert in the political process. These projects are oftentimes a result of community interest in making their area a better place to live; thus, a group will organize upon that principle or for a specific project. Or, a group of individuals may be appointed by someone in a leadership position for some specific project. This paper is going to explore the members of former Governor Tom McCall's Venereal Disease Task Force as they proceeded to determine the reason for the highly widespread incidence of venereal disease in oregon and to determine the means of combating this menace that afflicts one out of thirty oregonians. This task force, which will be detailed later, is one to which I was appointed in 1972. I was one of several that were appointed in an effort to review the venereal disease problem and plan an action-based method to help eradicate the disease. Thus, this paper will reflect my participant-observer status on the commission.

The Venereal Disease Task Force resembled an influential organization with community wide impact. As section two will discuss, the group was chosen primarily for their influence and ability to affect the community by a number of various methods. It was a combination of these methods and the people that made the thing work. 
However, I originally questioned whether it actually was the people themselves that determined the success of the task force, i.e. Was the task force effective as a result of the participants and their community influence, or was the effectiveness simply generated from hard work and a great deal of co-operation?

During the preparation of this paper I discovered several factors which oriented themselves to the same question. During this same period I felt more and more that it was the individual participants and their role in the community that provided the necessary components to make the task force successful. One of the purposes of this paper is to explore the operation of a politically appointed group chosen to complete a specific project; the other, to determine if this influential role these people enjoyed opened the avenues towards accomplishment. One of the most significant factors in analyzing the operation of the task force and/or the individual influence of its members was each individual's response to the entire project. Because this response is of such significance, I devised a questionnaire (see page 85) and mailed a copy to each participant. The findings and results of this study are representative of the questionnaire and its responses.

Throughout this paper I will begin initially looking at the nature and extent of venereal disease itself as well as its present status in oregon. Secondly, I will explore 
4

the appointments to the Venereal Disease Task Force by

Governor McCall, why they were appointed, and what kind of accomplishments each had in the community. Thirdly, I will examine what goals the task force, various sub-committees, and each individual considered. Fourthly, I will look at the accomplishments of each group and individual, and finally an evaluation of accomplishments, the influence used toward these accomplishments, and the entire task force as an entity. 
THE PROBIEM

Venereal disease has plagued mankind for centuries and has been present in the United States since its discovery. Gonorrhea, which is a type of venereal disease, has been recorded by historians since Biblical time with profound effects on the social development of man. Syphilis, another type, is more recent with its introduction sweeping through Europe in the mid-fifteenth century.

Only recently has the incidence of venereal disease reached epidemic proportions in oregon. It has now become a serious threat to public health. Venereal disease is now the most frequently reported communicable disease in Oregon, second only to the common cold in total numbers infected annually. During 1973, there were more than 11,000 cases of venereal disease reported, and in 1974 , almost 12,000. The 1975 figures showed a slight decrease to 11,500 . As recently as 1955, only 1100 cases were reported.

It has been suggested that this increase is a result of improvement in the procedures of reporting communicable diseases. Nonetheless, the oregon State Health Division estimates that for each reported case, some five go unreported. 
Nationally, gonorrhea has been increasing at a rate exceeding 15 percent annually. In oregon, the number of cases reported has doubled in the past five years. At the time of this study oregon ranked twelfth in the country in the incidence of venereal disease, with Portland ranking number eight among cities of 200,000 population or more (see Tabie 1, page 94).

Although one usually thinks of gonorrhea and syphilis when discussing venereal disease, the term venereal disease actually is a generic term used to describe a number of diseases. These diseases are caused by organisms which are transmitted either by sexual intercourse or by intimate bodily contact involving the sex organs, mouth, or rectum. There is incidence of other venereal diseases in oregon which include chancroid, granuloma, inquinale, and lymphogranuloma venereum. These are quite highly contagious and infectious but represent only a minimal percentage of the cases and in no way approach epidemic levels. Consequently, the main focus in the fight against venereal disease has emphasized syphilis and gonorrhea.

Gonorrhea, by far the most common of the venereal disease, is caused by the bacteria neisseris gonorrhea. Infectious gonorrhea usually remains localized whereas syphilis may involve the entire central nervous system, as well as other parts of the body.

The symptoms of infectious gonorrhea normally appear in the male three to five days after exposure, 
although the incubation period sometimes may be as long as one month. Because many cases are asymptomatic, symptoms may not appear at all in up to 30 percent of infected males. Early symptoms of an infected male usually consist of a discharge of pus from the penis and concurrent inflammation of the urinary canal resulting in a painful, burning sensation with urination. Those males that do show symptoms are fortunate because they will usually become motivated to seek treatment. However, if treatment is not obtained, the disease may spread along the urinary tract causing permanent damage--including sterility.

Gonorrhea in the female is more difficult. Somewhere between 50 and 80 percent of all females are asymptomatic. Even those who do develop symptoms, many confuse them with other less serious vaginal discharges and fail to seek treatment. Because a majority of the infected females are unaware of the infection, they have the possibility of spreading the disease to other males quite easily. Oftentimes these women are still unaware of the infection until they are brought to treatment by a concerned male partner or through the case-finding process (this process discussed on page 13). If the female does not seek treatment at all, the infection could spread to the reproductive tract causing a pelvic inflammatory disease resulting in sterility. If this occurs, the patient will experience fever, abdominal pain, 
and frequently requires hospitalization and possible pelvic surgery.

Rectal gonorrhea is frequently encountered in the treatment of male homosexuals. Here, too, more than half of the patients encountering infection are asymptomatic. This also leads to serious complications.

Untreated persons are extremely susceptible. to gonococcal infections occurring in other areas of the body by the circulatory system. The most frequently recognized complication of gonococcal infection is arthritis, but the heart, liver, nervous system, and other organs may become damaged as well. Untreated gonorrhea is the most common cause of sterility in both males and females in the United States today.

Other than sexual contact with an infected partner, other modes of transmission are possible. An infected pregnant woman may infect her baby at birth as the baby passes through the vagina during delivery. This could result in blindness which is the reason all babies are treated with silver nitrate drops in their eyes at delivery. In very rare cases, small children may be infected by nonsexual but intimate contact with an infected person. This is quite rare, however, estimated at 0.1 percent of known cases.

Syphilis, on the other hand, is caused by a.microscopic, spiral shaped organism called the treponema paliidum. It is also transmitted by hetero or homosexual 
contact. The first sign of infection in either male or female is a chancre (pronounced shanker). The chancre is a small sore that usually appears at the site of infection within ten to ninety days from contracting the disease. In the male, the chancre usually appears on or around the penis. In the female, it may be inside the vagina or on the outer part of the genital tract. However, the chancre may also appear in the mouth, on the lips, or in the rectum or on other mucous membranes of the body where contact occurred. The chancre has the appearance of an open ujcer or blister and is generally painless.

The chancre usually appears within one to five weeks if left untreated. Iater, the chancre may disappear but in no way does this mean the infection has left the body. Syphilis occurs in three stages. The first, or "primary" stage occurs with the appearance of the chancre. Sometimes even with blood tests syphilis cannot be detected at this stage. About six to eight weeks later another set of symptoms develop, producing the "second" stage. At this time symptoms appear as a rash that can be scarcely noticed or quite severe. The rash may also be accompanied by severe headaches, fever, sore throat, ailments of the eyes, or loss of hair. These secondary symptoms may last two to six weeks and may re-occur over a period of many months. Blood tests at this stage are always positive. After about four years, syphilis passes from its second stage to its late stage. At this stage, it is 
usually no longer possible to transmit to a partner. At this time, the organism may be lodged in virtually any organ of the body including the heart and the brain. If the organism still goes untreated, the possibilities of chronic brain damage, blindness, crippling, heart disease, and perhaps death are apparent.

Congenital syphilis can occur if a woman has syphilis before or during her pregnancy. However, if the mother is treated before the eighteenth week of her pregnancy, prevention of the infection is assured.

Gonorrhea is by far the most common of the venereal diseases today and the most prevalent bacterial infection of adults in the United States (see graph 3). Syphilis ranks third, ranking after gonorrhea and chicken pox in total reported cases. (It should be noted that while 80 percent of all venereal disease patients are treated by private physicians, only 15 to 20 percent of these cases are reported to the State Health Division which is required by law. Thus, actual figures could be staggering.) [Incidence of venereal disease is climbing so rapidly, that public health officials predict that in just five years over five million cases of venereal disease will be reported in a single year nationally.] [Additionally, in Oregon alone, if the trend continues, one of three students that are presently in high school will have contacted a venereal disease by the age of twenty-five.] This fact identifies oregon's worsening problem even as it relates 
to the nation as a whole.]

A popilar misconception of venereal disease is that it strikes only the lower and lower-middle class, the poor, the uneducated, the minorities. However, venereal disease knows no boundaries. It affects all age groups, males and females, and crosses the entire spectrum of social and economic classes. This "nevercould-happen-to-me" attitude coupled with the assumption that venereal disease has been conquered with the advent of antibiotics, has seriously impeded public health efforts aimed at the control of syphilis and gonorrhea. Additionally, there is an attitude that venereal disease is an attitude of punishment due those who engage in sexual activity. Those who believe this fallacy tend to hinder educational efforts and epidemiological treatment.

Presently, the highest incidence of venereal disease occurs within the sexually active segment of the population, but in 1973 there were 103 cases reported affecting children under the age of fourteen in Oregon alone. Venereal disease is especially common among the fifteen to twenty-five year olds. This group comprises approximately sixty-five percent of all reported cases. A total of eighty percent of reported cases come from those fifteen to twenty-nine years old. Those in this age category are more apt to seek treatment at the free health clinics. Those in older age categories tend to seek 
treatment from private physicians, whom, as has been noted, oftentimes fail to report the case to the public health department. This older group successfully seeks anonymity through treatment in the offices of private physicians. Because of this association, it is becoming more of an urgent problem identifying these people and arresting the infection as it proceeds throughout that age segment.

Treatment for venereal disease is now quick and quite simple. Most cases of syphilis and gonorrhea are cured by two injections of penicillin administered in one clinic visit. Many people feel that the treatment is long and painful as it was prior to penicillin. This fear also inhibits any desire to seek help. Quick treatment coupled with extremely advanced laboratory services in Oregon has improved the treatment procedure expeditiously. Thus, the problem now is not treating the patient, but finding those who need the treatment.

If enough problems have not already been identified, fill further complication continually impedes the work of the public health officials. As has been mentioned, a high percentage of gonorrhea infected women show no visible symptoms (asymptomatic). It is equally difficult to discover cases of infectious syphilis in women since early symptoms may be painless, may go unnoticed, and frequently go away without treatment. As well, approximately thirty percent of gonorrhea infected males are asymptomatic 
and this number is increasing. And, unfortunately, the gonoccoccus germ is becoming more resistant to penicillin. Within the last few years, the penicillin treatment has had to be doubled to 4.8 million units to successfully kill the germ. a. - W With all these negative elements, it can readily be Interpreted that the task of combating venereal disease is enormous. Fortunately, however, many implementations have significantly helped to coerce the public into recognition of the problem and have significantly helped the case-finding and epidemiological attempts to mature. Oregon presently has the most advanced control programs in the nation. These control programs are based upon an epidemiological case-finding approach, which is the field science concerned with factors and conditions that determine the occurrence and distribution of the disease. Control must be based in this manner because no case of venereal disease can occur in isolation because of the unique manner in which the disease is transmitted. The major activity of this case-finding approach is that of interviewing the diagnosed patient to determine from whom the disease was most likely contacted and to whom it may have been transmitted. This epidemiological approach is the only means to try and isolate the disease. Presently, there are ten epidemiologists in oregon. All are federally funded and all specialize in venereal disease. Their goals are to identify and to bring to 
treatment infected persons in the fastest possible method in order to avoid spreading the disease further. The infected persons are found in a clinic, through private physicians, contacts of others whom have been treated and interviewed, or screened elsewhere. These persons are interviewed confidentially and encouraged to list their contacts. At that time, either the patient or interviewer will attempt locating all contacts for possible treatment. Unfortunately, because of the limited number of staff, this approach is being used with reported males only. The males contacts are investigated which will assist in the location of the females, but still only the males who initiate the treatment are interviewed as such.

Population mobility poses a serious problem in case-finding. There is a state-wide case-finding network between cities and counties in oregon. For contacts reported in other states, there is a case-finding network operated by the National Center for Disease Control in Atlanta. Working with the National Center is more complicated and less rewarding than with the state-wide network because of proximity. However, it has been helpful. oregon is unique in its case-finding process in that it is the first state to have developed a decentralized laboratory program involving thirty different incubator sites throughout the state. This helps to quickly confirm the infection. Another feature is that clients of family 
planning clinics are also being screened when a pelvic examination or a pap smear is requested.

The introductions of these programs has aided public health officials significantly. Since no serum has been perfected and the unpopular use of the condom is the only sure way to avoid contact with an infected person, more methods of prevention are necessary to combat this ever-growing disease.

Because venereal disease is spread by human sexual contact, its control is closely associated with human attitudes. Altering human attitudes is slow and frustrating enough, but extremely so when working with sexual behavior. Thus, the best way to fight future infection of venereal disease is by education.

It is much easier to educate a young person with a mind that is relatively fresh and naive than to change the attitude of an adult. One of the best facilities we have for this purpose is the school system. If the concepts and ramifications of venereal disease are explained properly to the student in his early teen years, he could better understand its meaning and significance, while at the same time learning how to prevent it. Obviously, this would not eliminate the problem in its entirety, but students would grasp the concept better than they now do, and at least be better aware of it. In 1973, a survey was conducted in oregon by the Governor's Commission on Youth. The students in the survey 
were asked about their feelings in regard to venereal disease education.

When asked if there should be more classes in school where students could learn about venereal diseases, 71 percent said yes, 15 percent said no, and 14 percent offered no opinion.

When asked if "...kids in the sixth or seventh grade ought to be taught about venereal diseases," 75 percent said yes, 16 percent said no, and 9 percent had no opinion. Interestingly enough, when the same students were asked whether or not they personally knew someone who had had a venereal disease, one out of three said yes. Students said they thought the family was the ideal source of venereal disease education, but as a matter of fact, most of what they knew about venereal disease they had learned in school. While students agreed with the concept of family education they nonetheless firmly supported the reality of public school education in terms of venereal disease.

The survey indicated that the majority of youth in Oregon would welcome expanded venereal disease education in their schools. A further indication of this educational need is that of the more than 11,000 reported cases of venereal disease, almost one-fourth occurred in young people of high school age.

The students firmly supported the reality of public school education in terms of venereal disease, the survey 
also indicated that the majority of youth in oregon would welcome venereal disease education in their schools. Presently, some venereal disease education is being taught in the schools. Prior to 1973, although there was some venereal disease education being taught, many teachers around the state feared recrimination from their principal or school board. Moreover, principals also feared recrimination from the school board and the parents. However, the 1973 Oregon legislature, after being heavily pressured by the Governor's Task Force and the State Health Department, introduced two bills that were passed to alleviate this problem (this will be adequately detailed in a later section). The bills, Senate Bill 882 and Senate Bill 883 initiated a legislative drive towards school education against venereal disease. Senate Bill 882 provided a pool of $\$ 50,000$ to be used by public school districts in oregon that would send a teacher for venereal disease training in a venereal disease workshop. The bill established twenty-three twoday venereal disease education workshops. The monies appropriated were dispersed by the State scholarship Commission for the purpose of defraying the living and tuition costs of certified teachers enrolled in the courses. Three additional one-day workshops were held in the Portland area schools in late April 1974. A total of 209 teachers and community members attended the workshops. The program was in co-operation between the State Health Division and the State Department of Education. This program met with 
tremendous success, using all the money available. Senate Bill 883 precluded any recrimination of any teacher who instructed venereal disease prevention and fact to his students. This bill has helped to eliminate the omnipresent fear in all school districts.

other current educational tools used in schools include a teacher-student reference guide for venereal disease educators. This reference guide was compiled by the state Health Division and contains all information needed to conduct venereal disease education classes. The guide includes a teaching unit with suggestions for instruction about syphilis and gonorrhea in junior high and high school.

Although venereal disease education to youth is obviously important, the state cannot ignore the adult sector of the community. However, this is expressly what had been happening to educate the adult community--nothing. Basically, the only exposure adults had to the significance of venereal disease was word-of-mouth, periodic public service spots on television, and periodic articles in newspapers and magazines. What the adult sector needed to help them comprehend the problem was facts and measures of prevention and treatment. But prior to 1973, there was no responsible means that had adequate financing to alert the public. Prior to 1973 there were no organizations to pressure the school board and the legislature to significantly intensify the battle against this disease which had 
19

now become the the common cold's only competition as a continuous communicable disease.

Consequently, it became obvious something had to be done. 


\section{ADDRESSING THE PROBIEN}

As Section I discussed, the problems associated with venereal disease had become increasingly acute. Since a large proportion of those afflicted with venereal disease were between the ages of fifteen to twenty-four, the members of the Governor's Commission on Youth became quite concerned.

The Governor's Commission on Youth is a board of nineteen members selected from the community by the Governor to serve for three years. The Commission was formed by Governor McCall in his first term of office to assist him in decision-making concerning youth or youthoriented programs. Youth, for the commission purposes, is defined from ages zero to twenty-five years. Some of the commissioners have been re-appointed several times and even today a few still serve that had served on the original commission. A tremendous variety of occupations, professions, interests, and personalities are found on the Commission, and any decisions emanating from the group have been considered by several types and ages. The Commission has tremendous respect from the Governor, the legislature and youth-oriented agencies throughout the state. 
Because the Youth Commission concerns itself with the problems of youth, the state Health Department came before the Commission in 1972 relating the tremendous growth rate of infectious venereal disease among oregon's youth. Henry Horton, director of the venereal disease program of the oregon Health Division referred to the gonorrhea epidemic as pandemic - worldwide - and "those who considered venereal disease anything less than at epidemic stage do so from lack of knowledge about the disease and about the people infected."1 Horton continued by emphasizing the need of a recognized, well-respected group of citizens to form and influence the Governor, the legislature, and the public towards awareness of the problem and how to prevent contact with the disease. Horton concluded that the Youth Commission had the power to go to the Governor and request that such a body of persons be appointed and charged with the responsibility of researching the venereal disease problem and finding solutions to alleviate the problem.

In response to Horton and the oregon state Health Division's request, the Commission, led by its chairman Clay Myers, contacted Governor McCall and presented the request to him along with the Commission's full support. On December 19.1972, the Governor, addressing the

1 Introductory remarks to initial meeting of Governor's Task Forcs on Venereal Disease by Henry Horton, oregon State epidemiologist, 2 May 1973. 
Commission stated:

I appreciate and I have been impressed by the willingness of members of the Governor's Commission on Youth to involve yourselves in significant issues over the past year.

The statewide conference on Community Use of Schools you sponsored last January went even further than your charge, pointing up how educational opportunities could be expanded for all ages.

You've made a great contribution through your continuing participation in revision of the Juvenile Code. Your program calls for you to work on it even more, but you are near the finish of this task, and I will value highly your final recommendations.

You also worked for approval of the federal Youth Conservation Corps Act--which now provides new opportunities for our young people to be involved in preservation of our natural resources and scenic beauty.

Discussions and debates you generated on Ballot Measure 9 helped expose and defeat a major threat to our educational system.

I think your concern for youth was manifested most recently in the venereal disease problem in oregon. We're facing a gonorrhea epidemic, and you're doing a major service by focusing public attention on the problem. We can't tolerate the old notion that venereal disease is not a fit topic for the media or the schools. Institutions that are reluctant to face up to this most serious public health problem must change.

The Youth Commission has a unique position among youth-centered organizations in oregon. You are not charged with the responsibility of the delivery of services to individual children and young adults but with seeking out and attempting to change institutions and laws that repress rather than assist oregon youth.

In my Executive order establishing this Commission, I charged you with the responsibility of stimulating interest, study, planning and action to create opportunities for the children and young adults of oregon so that they might achieve their highest potential.'

That was four years ago. Now I repeat that charge, and in doing so emphasize your opportunity to address yourselves also to the identification and correction of those institutional failures that prevent our youth from reaching their highest potential.

Chairman Clay Myers responded to the Governor's remarks: 'Thank you for your kind words of commendation and for the clarity with which you reiterated the task of the Youth Commission. 
In keeping with your mandate to address ourselves to those institutional failures which prevent young people from reaching their highest potential, I am today appointing a broadly-based, statewide Task Force to review the extent and nature of the venereal disease problem in Oregon. I shall ask the Task Force to report on the effects of venereal disease, not only on the individual, but also on the family and on society.

The Task Force will be asked to report on the availability and application of the diagnostic, preventitive, epidemiologic, and educational tools for the control of venereal disease in oregon.

Further, the Task Force will be asked to make recommendations to the Governor, to the Iegislative Assembly, to the State Health Division, and to other appropriate individuals and agencies, on the feasibility and priorities required for launching a stepped-up control program, and the relevance of the program compared to other social ills and medical problems in oregon.

The Task Force will be asked to make recommendations on the need for further research on prevention and treatment; on new legislation designed for control of venereal disease; on sources and methods of funding the activities required to control venereal disease; and on appropriate educational programs for the public schools of Oregon.

Finally, the Task Force will be charged with the responsibility of informing the public, through the news media, of its progress, findings and recommendations.

With the advice and unanimous consent of the Executive Committee of this Commission, I have named Representative Lewis Hampton as Chairman of the Oregon Venereal Disease Task Force. Through the findings and recommendations of the Task Force we will indeed be able to exert a constructive influence on the institutions of oregon in their efforts to control the problem of venereal disease.'2

The selection of members was made mostly by clay Myers with the inspection and confirmation by the Governor. The determination of just who should serve was a process of choosing leaders in the various fields that would have a

2 Governor's Commission on Youth, Minutes of Meeting of Governor's Commission Members, Meeting of 19 December 1972. 
basic understanding of the problem and what should be done and/or those who could help affectuate any recommendations expeditiously and responsibly. Myers then contacted each individual chosen and asked them if they would care to be appointed. Surprisingly, with the professional schedules that most had, they all accepted. Additionally, Myers contacted six persons related in the fields of health and/or venereal disease and requested they be consultants. All of these persons accepted as well. This group, identified below, congregated at their first meeting on May 2, 1973.

The Governor's task force on venereal disease: Representative Lewis Hampton, chairman of the task force, age 41, attorney, legislator. Representative Hampton has been quite active in his career, particularly in the legislature. He has served on the House Judiciary Committee, the House Consumer and Business Affairs Committee, the House Energy Committee, State Bar Committee on Uniform State Laws and Uniform Jury Instructions; Governor's Commission on Youth. Hampton felt he was appointed because of his previous work with the Governor's Commission on Youth and also because he could use his legislative position to assist the goals of the task force.

Bert Simmons, age 39, educator. Mr. Simmons has been the President of Oregon Association of Secondary Principals, has served on that association's executive committee other than president, has served with the oregon 
Speech Association and the Confederation of Oregon School Administrators, also being president of that confederation. Simmons felt he was chosen to the task force because of his educational background.

- Mary Dannen, age 58, housewife. Mrs. Dannen, as a "housewife" has served her state extremely well as a volunteer. She has served on the Governor's Commission on Youth, the Volunteers in Court, Committee on Children's Emotional Health, Committee on March of Dimes, the American Cancer Society Education, Committee Board of Linn-Benton Community College, Nominations Committee and Legislative Committee for the National Parent-Teacher Association, and President of the Oregon Congress of Parent-Teacher Association. Mrs. Dannen feels she was chosen because of her direct affiliation with the state and national Parent-Teacher Association and because of her known interest in health education and related subjects.

Dr. Wilford Tavlor, age 50, chiropractic and naturopathic physician. Dr. Taylor has served on the State Board of Health and feels that he was appointed because of this position on the State Board of Health along with his membership in the Oregon Association of Chiropractic Physicians.

W. Ronald Powell, age 36, advertising. Mr. Powell has been serving on the Tri-County Community Council, Venereal Disease Action Council (VDAC). Mr. Powell is also president of the state's largest homosexual organization and feels that this is why he was chosen to the task force. 


\section{6}

Jack M. Bull, age 33, pharmacist. Mr. BuIl has not served on any commissions or committees recently but the Governor felt that the profession of pharmacy should be represented, and $\mathrm{Mr}$. Bull was appointed.

John Snider, Jr., age 31, sales manager of Pepsi Cola Bottling Company. Mr. Snider had served on the Governor's Commission on Youth and represented the business community on the task force. Mr. Snider is from Medford and felt he was chosen to carry forward any goals to southernoregon.

Iois Miller, age 45, Registered Nurse, part-time real estate broker, housewife. Mrs. Miller has led an extremely active career in public service. In 1974 , she was named oregon woman of the year because of her active interest in so many areas. Recent committees and commissions upon which she has served include: Oregon State Hospital Siting Committee, a sub-committee of State Health Commission; Tri-County Community Council, Health Committee; Oregon Health Council, Director; Volunteer Nurse Program, Franklin High School, Chairman; Southwest Hills Residential League, Director; Metropolitan Women's Club, Vice President; Washington County Medical Auxiliary, Director; Multnomah County Medical Auxiliary; Oregon State Medical Auxiliary; American Medical Association Auxiliary, Legislative Chairman; Oregon Republican Women, Legislative Chairman; Oregon State Parent-Teacher Association, Health Chairman; Young Women's Christian 
Association, Camp Committee; School Health Advisory Committee, Multnomah, Intermediate Education District; Good Samaritan Hospital Alumni; Oregon Board of Realtors; Clackamas County Board of Realtors; Ainsworth, Iincoln, Benson, Wilson Parent-Teacher Association; Partners of America, secretary. Lois has been so incredibly active, especially in areas of health education, that her participation on the Task Force was bound to be exceptional. Iois feels her appointment was because of her interest in health education.

H. Joe Myers, age 50, Assistant Director Oregon state University Extension Service. Mr. Myers has served on the White House Conference Committee for Marion County and also the statewide Youth Conference in 1965. Mr. Myers also has served on the Governor's Commission on Youth. Mr. Myers feels he was chosen for the Task Force because of his work on the Governor's Commission on Youth.

Robert Y. Thornton, age 64, Judge, Oregon Court of Appeals. Judge Thornton has led an active life in community service. He is currently serving on the state of oregon Traffic Safety Committee and was quite active on the National Association of Attorney Generals while he was Attorney General of oregon. His extreme knowledge of the legal profession and how it works was cited by the judge as to the probably reason for his appointment.

Claudia Webster, age 37, health education consultant for the state of Oregon. Mrs. Webster has served on the Family Planning Advisory Board in San Jose, California, 
as well as chairing the Annual Portland Metropolitan Interagency Family Planning Council for two years. She has also been involved in public education and research projects and several activities and programs sponsored by the Methodist Church. Mrs. Webster has worked with venereal disease previous to this appointment and has also heavily supported the use of the condom for both family planning and fighting venereal disease. This work, she feels, prompted her appointment.

Gregory Wolfe, age 53, educator, president Portland State University. Dr. Wolfe has served on United States Department of State "Stag" Program, the Fletcher School of Iaw and Diplomatic Visitors Board, the oregon Symphony, and the Urban Land Institute Renewal Board. He served as president of Portland State University before his current position as administrator at American University in Washington, D. C.

Randolph L. Miller, age 27, vice president Milcor, Incorporated. Mr. Miller has been quite active in civic affairs and was a commissioner of the Governor's Youth Commission at the time of the appointment. Mr. Miller worked diligently on several sub-committees of the commission and was appointed because he was willing to work on this task force. Clay Myers felt that the business community should be represented.

In addition to the above names, there were six others that were appointed but who did not respond to 


\section{9}

my questionnaire. However, only one of them contributed to the Task Force, so the results of the others would be meaningless to this study. The one appointee who was a contributory factor in the Task Force accomplishments was Shirley Petrie, a Portland stockbroker who could not find the time to respond; however, she deserves ample credit for her work with the schools and their venereal disease programs.

In addition to the appointments to the Venereal Disease Task Force, seven consultants were also asked to serve in an attempt to provide the professional background in the area of health to the Task Force. It was felt that the team of consultants could inform Task Force members with the knowledge in health and venereal disease that would be necessary for the Task Force members to better understand the problem. Additionally, a better and more comprehensive grasp of venereal disease ideology and its effect on the public could aide any decision making by the Task Force.

It may be advisable here to clear a question that has often been posed concerning the consultants. The question is: "Why do you need a task force appointed by the Governor when the members do not necessarily understand or relate in any way to venereal disease, while the consultants have all the necessary credentials to complete the task force goals?" The answer may best be in the response given to me by Clay Myers. Clay explained that 
the consultants are employed by the various governmental units and are paid to do their job. The executive and legislative branches of the state government recognize this fact and basically believe that since these people are doing the job that they have been charged to do, anything they request will be in the line of duty accompanying their position. Thus, when budget requests become larger than expenditure allowances, all these people with their requests should be treated equally. However, when a group of volunteer citizens, who have worked towards solutions to benefit the public make a similar request, then more credence and attention should accompany the request. Moreover, when this group of volunteer citizens are influential or community leaders with political power, additional consideration automatically follows. (This form of power will be detailed in a later section.) The consultants chosen also have impressive backgrounds:

Hugh H. Tilson, M.D., age 35, health officer. Dr. Tilson serves on the comprehensive Health Planning Association of the Portland Metropolitan Area, is president of the Oregon Conference of Iocal Health Officers, is serving on the Tri-County Community Council and is a member of the Reed College Alumni Board. Dr. Tilson directs the Venereal Disease Clinic in Portland and feels his appointment as consultant to the task force was because of his expertise on venereal diseases. 
John A. Googins, M.D., age 52, epidemiologist. Dr. Googins serves on the Comprehensive Health Planning Council and served on the consultant staff because of his extensive background in epidemiology.

Henry B. Horton, age 41 , public health advisor. Mr. Horton is manager of state venereal disease unit with Mr. Cowne (below) as his assistant. Mr. Horton was chosen because of his extensive work in venereal disease (twelve years as an occupation) and understanding of the problem. Donald R. Cowne, age 31, public health advisor. Mr. Cowne worked only as a part-time consultant along with Mr. Horton and was chosen for the same reasons as was Mr. Horton.

Noel Rawls, M.D., age 59, physician and health officer. Dr. Rawls was the Oregon Medical Association President in 1969-1970, served on the Board of Health 1971-1973, is presently serving as chairman of siting committee of Oregon Medical Association, commissioner on the Oregon Regional Medical Program and advisor to the Medical Examination Board. Dr. Rawls is an authority on venereal disease and was chosen because of it.

A.K. Hottle, age 46 , public administrator of health and social services. Mr. Hottle has served on the Comprehensive Health Planning (Iane County) Committee, the Health Legislation for Comprehensive Health Planning and Health Council, Council of Government Human Resources Committee, Mental Health Center Committee, State Public 
Health Association, and several Iane County committees. Mr. Hottle encouraged the Lane County Committee on Children and Youth to concern themselves with the problem of venereal disease which in turn encouraged the state committee. Because of this deep concern of the problem, he was appointed.

Ien Tritsch and Kevin James Iee, health specialists for the Department of Education. These two men shared a dual position on the Task Force consultant team. Both have served on the Primary Prevention Task Force and the Drug Abuse Prevention Task Force as consultants. Both were chosen because venereal disease education related to their responsibility as health educators.

The total group reflected a contribution of minds that could add input from several different backgrounds and interests. The consultants had the knowledge and familiarity of the venereal disease problem while the members had the aptitude to understand the problem and the resources to do something about it. One of the most significant factors of the membership, however, was the contacts and influence each maintained in the community. Each member, through his occupation/profession or various associations, had the ability to affect the community either directly or indirectly through organizations capable of affecting the community. Obviously, the position of each member in the community coupled with past performance in other civic projects was a major 
33

determinant in the Governor's decision as to whom to appoint to the Task Force.

This "community influence" proved to be a major factor in the effectiveness of the Task Force. The following sections depict and analyze this effectiveness as it is related to the life of the Task Force and its accomplishments. 


\section{III}

\section{ATTACKING THE PROBLEM}

The initial meeting of the Governor's Task Force on venereal disease occurred on May 2, 1973 at the Sheraton Hotel in Portland. All seven of the consultants were also present and they spent a good deal of this first meeting indoctrinating the members with the facts and history of venereal disease. The remainder of the session was a definite attempt to set both the long term and short term goals of the Task Force. Considering the Task Force was funded only fourteen months, it was recognized that these goals must reflect the time frame allowed. Thus, the following goals were established: Long Range Goal: (No time frame) Reduce the incidence of venereal disease among young people (0-25 years) in Oregon. Short Range Goal: (June 1, 1974) Prepare and present to the Governor's Commission on Youth a final report of the Oregon Venereal Disease Task Force. The final report to accumulate and examine information and data on which to base recommendations which when implemented through public and private resources will reduce and control the incidence of venereal disease in Oregon. It was unanimously regarded as essential that in order to prepare a final report as such, we would 
additionally need to formulate objectives to assist in such a massive project. Five distinct objectives were consequently formulated:

1. Review the extent and nature of the venereal disease problem in oregon with appropriate groups and individuals to indicate (a) the effects of venereal disease on the individual, the family, and on society with respect to suffering and economic costs; and (b) the availability and application of the diagnostic, preventive, epidemiologic, and educational tools for the control of venereal disease.

2. Make recommendations to the appropriate public and private agencies and community groups on state and local levels as to the feasibility and priorities for launching a stepped-up control program.

3. Report on the need and hope for further research on social as well as medical measures for the control of venereal disease with priority emphasis on prevention.

4. Make recommendations to the Governor on new legislation or changes in legislation designed for the control of venereal disease.

5. Ascertain and recommend possible sources and methods for funding the activities required to control venereal disease.

Possibly one of the greatest advantages of having such a broad-based committee is that the diverse backgrounds of the individuals allows for a wider selection 
of ideas. Additionally, the individual could form subcommittees and work directly with their own areas of special interest. The Task Force followed this type and formed five sub-committees: (1) School education, (2) Community education, (3) Fact-finding and report preparation, (4) Health, (5) Media and legislation.

Each sub-committee was immediately allowed to pursue the interests of the respective sub-committee and was given virtually unlimited constraints to do so. Throughout the term of the Task Force, each sub-committee formulated its own goals, pursued these goals, and directed themselves toward individual tasks. The Task Force met once each month and discussed the progress of each subcommittee and interchanged ideas. All of this interaction, it must be remembered, was basically toward one main objective--completing the study and writing the Task Force report. However, it became apparent that during the period of report presentation, that the Task Force members also were capable of affecting various institutions that were able to assist in the long term goal--that of reducing the incidence of venereal disease among young people in Oregon. Consequently, the various sub-committees began working with education, health organizations, the media, and the legislature to assist them in specific projects. Considering this type of activity was spurred strictly by the group itself and not by the body that appointed them, an interesting observation might be as to why each 
member chose to accept their appointment to the Task Force. The results of the questionnaire showed that basically there were three groups of reasons why each member chose to serve. All the consultants reported that they served because of the special interest of their employment, i.e. working with venereal disease. However, some were more emphatic than others about the specific need to control venereal disease. The second group accepted the appointment simply becalise they were asked and felt it a privilege to serve. The third group served out of special interests. Specifically, the high school principal served as a learning tool to assist the teachers in his school to instruct the students in venereal disease education. The chiropractor served to give representation to his profession. The registered nurse chose to serve so she could adequately train her nursing staff to deal with venereal disease. The housewife (also Parent-Teacher Association president) expressed a desire to extend ParentTeacher Association work to venereal disease control. Finally, the member representing the homosexual community warted to work with the gays to educate them on the huge problem in that community.

While all responses indicated they had a reason for accepting their appointment, very few had individual goals to accomplish. Actually, only the consultants had any tangible individual goals at all. Most of the consultants' goals centered around the need to raise the 
awareness of venereal disease, to obtain better statewide action against venereal disease, and to reach the youth in the schools. Also mentioned by a consultant was to upgrade the patient care capability within the venereal disease clinics and private physicians offices. These types of individual goals are the kind of goals I would think every member would have desired to have affectuated, but none of the members mentioned any of these. The only positive responses to this question was by two members whom stated they would hopefully see better awareness on the part of the public. One of these two responses did mention, however, that she would hope the public could someday better openly discuss the problem. Otherwise, no one had any individual goals. This surprised me because if they had a reason to serve at all, I would think they would have at least some desire to see something positive happen. Possibly the status of being appointed by the Governor motivated most members to accept the appointment. Maybe the feeling of becoming influential serving on an executive commission lured them. Without any goals, I see no other reason to join.

Although only a few members mentioned individual goals, several of them were quite effective during the life of the Task Force. At first participation was probably 75 percent and each individual worked through his own role on his sub-committee into his everyday occupation. With only one exception (me), each individual involved 
his task force work with his general vocation or profession. When asked what exactly was the personal role that each member assumed, the response completely fell into categories that reflected their everyday work. The consultants all replied that their role assisted in venereal disease expertise, supplying statistical information, budget information, and epidemiological information. Additionally, they supplied input and backing from health organizations and the Department of Education. Possibly the consultants greatest contribution was all the foot work they provided. Because of their direct involvement with venereal disease, it was much easier for them to give public speeches, draft letters to those involved, answer inquiries, and give direction.

The members, on the other hand, evaluated their role as a means to work within the system with those people who could directly cause changes to occur. For example, the Judge saw his role as giving advice on legislative programs and introducing several legislators to the efforts of the Task Force. Moreover, he felt he offered inside advice and experience in carrying out citizen action programs which he said he learned while he was a.ttorney general. The school principal rated his personal role as a means to stimulate implementation of educational programs into the schools through his office and contacts. The legislator felt his role was to co-ordinate and direct the specific goals through his legislative and influential 
channels which represented what the members desired to see accomplished. The member who represented the gay community specifically used his esteemed position amongst the gays to encourage said gays to seek advice and treatment for venereal disease. The housewife who was also president of the oregon Parent-Teacher Association probably put her influence to work more significantly than any. She maintained an enormous load of correspondence to mothers with school age children urging them to contact principals of schools in their area expressing an interest in venereal disease education. Concurrently, she urged these mothers to participate in any possible venereal disease program. Additionally, this member assisted in the formation of the venereal disease workshops (see page 57) which were highly successful. The participation of the pharmacist was well rewarded too, because the role he played through his position on the State Board of Pharmacy significantly influenced the passage of the condom bill which allowed condoms to be sold in vending machines. The nurse, who was also director of the Oregon Health Council, was able to acquire approximately fifteen speaking engagements with various organizations to both educate them regarding venereal disease and to initiate programs that would allow the organizations to further educate others regarding venereal disease. She also corresponded with seventy-five statewide organizations requesting support and interest. She felt her 
personal role was to work with the various organizations with which she had worked previously. Another member, the assistart director of oregon state University's Extension Service, used his position at Oregon State University to feed input to the school newspaper which in turn published the works of two manuscripts dealing with venereal disease. He also placed a telephone survey to educators in rural areas to gain an overview of the attitude of rural school systems regarding venereal disease.

Thus, all the members that responded to the survey used their occupational position to assist them in effectuating any participation they enjoyed on the Task Force. My contribution was the work I completed with the media. I contacted virtually every television station in the state and approximately twenty radio stations. Each station cooperated by running public service announcements repeatedly over a given period of time. The Portland stations responded best and I appeared on several programs discussing the problems of venereal disease. Additionally, I contacted several newspapers which also cooperated by featuring articles about venereal disease. I did not intend this type of activity to be my role on the commission, but because of my contacts at some of the stations and newspapers, I was able to realize progress with these types of media.

In the questionnaire (see sample questionnaire) I 
had intended and hoped that each question would lead into the next one. I had hoped that the responses would become more specific as each question delved deeper and deeper into each members individual participation. Consequently, I thought possibly the actual influence each member enjoyed in the community would come out unintentionally as each question would bring deeper and deeper involvement. Thus, after asking each member what their personal role on the Task Force was, I asked them what means and methods they used to fulfill this role. Unfortunately the responses to this question stopped far short of what I wanted--a statement alluding to the fact that their means and methods were that of the assistance of other community influentials. Instead, I got answers such as: (1) Frequent attendance at meetings, (2) Speaking when I felt I had something to suggest, (3) Correspondence, (4) Distribute information, (5) Used consultants as speakers, (6) Time.

Obviously, I was extremely disappointed. I thought that at this point I would ascertain the actual reason the Task Force accomplished as much as it did: Member influence in the community. Surprisingly, what actually did evoke this much needed response was not an indirect equivocal question, but a direct question specifically asking each member if he thought his influence in the community played an important role at that time. (I put that question in the questionnaire just in case my other tactics did not 
work.) Although this response will be detailed in a later section. I would like to mention that the individual community influence definitely assumed a large part in the role each member played whether intentional or not. (Detailed in Section 4.)

The initial Task Force concluded its work in June, 1974 with its short term goal accomplished: The preparation and presentation to the Governor's Commission on Youth a final report of the Oregon Venereal Disease Task Force. Many other accomplishments will be revealed in a later section, but the final report was the main objective. This final report listed several recommendations (see Appendix) to (1) The County Health Departments, (2) The State Department of Education, (3) The Legislative Assembly, (4) The Oregon Board of Pharmacy, (5) The Oregon Medical Association, and (6) The State Health Division with the thought that if implemented through appropriate public and private resources, measurable progress could be made in reducing the incidence of venereal disease in oregon.

However, there was also a seventh recommendation which advised the existing oregon Venereal Disease Task Force to become an action agency to:

(1) Plan and implement a continuing program to increase public awareness of venereal disease;

(2) Assist County Health Departments in improving the organization and management of venereal disease clinics, 
in up-grading the quality of care provided, and in providing facilities which maintain reasonable standards of privacy and dignity for patients;

(3) Assist communities in establishing venereal disease action committees (VDAC) to support educational and control efforts in each community; and,

(4) Encourage pharmacies to display conaoms and venereal disease information in such a way that they are readily accessible to all customers.

The existing Task Force had no power to appoint itself as the action agency to pursue these recommendations, but we could encourage the Governor to do so. Consequently, Chairman Lewis Hampton met with then Governor Tom McCall and requested such an action agency be appointed. McCall granted the request and mandated that such an agency be appointed. No new funding was provided; however, the Governor allowed the use of the staff of the Governor's Youth Commission for the newly appointed agency. This actually provided a continuation of staffing because there was one staff member working for the Youth Commission that had not been employed by the Commission previous to the original Venereal Disease Task Force. The Governor allowed this position to be funded (via emergency funds allocated to Children's Services Division) for one more year.

At this point the staff and Chairman Iewis Hampton determined which of the existing Task Force members should 
be re-appointed. Criteria used for re-appointment was simply whether the member wanted to serve and whether or not the member had been active enough to warrant re-appointment. The intent was to remove those individuals whom least contributed to the Task Force. Since only a few significantly contributed to the success of the Task Force, only eight were asked to serve. The remainder were appointed by the executive committee of the Governor's Youth Commission. A total of nineteen were asked to serve. The consultants remained the same. Basically, the new appointees were asked to serve for obvious reasons. The Task Force again needed a well-rounded group that could expedite the objectives of the Task Force and who would be influential enough to direct ideas to appropriate people and/or agencies. Thus, it was necessary to consider the positions of the eight that remained on the Task Force from the original appointment before chosing new members. The eight originals were: (1) Mary Dannen, President Oregon Congress of Parent-Teacher Association; (2) Donna Hill (did not respond to either questionnaire); (3) Lois Miller, registered nurse, volunteer in numerous committees, real estate broker; (4) Randy Miller, Governor's Youth Commission, businessman; (5) Shirley Petrie, stockbroker, (did not respond either); (6) Ronald Powell, represented homosexual community; (7) Wilford Taylor, chiropractor; (8) Robert Y. Thorton, Judge, Oregon Court of Appeals. 
Reflecting the eleven who were newly appointed, only seven responded to my questionnaire. These seven were:

Don H. Dils, age 45, planning and finance manager of Iloyd M. Hill, Incorporated. Mr. Dils was appointed chairman of this Task Force with the feeling that his astute administrative ability would assist and guide the direction of the committee. He had previously served on the Governor's Youth Commission, was first Vice President of Oregon United Appeal, served on the Governor's Manpower Development and Selection steering Committee, was chairman of the Corrections Education Commission and served in Managemert 1970 s Task Force.

Max H. Parrott, M.D. Dr. Parrott was serving as president of the American Medical Association at that time.

Bishop Matthew Bigliardi, D.D. The Right Reverent Bigliardi is the Bishop of the Episcopal Church of Diocese of oregon.

Phyllis Bergen, Ph.D., age 40, clinical psychologist. Dr. Bergen has served on the state Board of Psychologist Examiners, a professional licensing board.

Nellie Fox, age 51, business representative AFL-CIO, for Local 1092 Retail employers. Mrs. Fox has served on an advisory council on sex discrimination. She has also sponsored volunteer work for Planned Parenthood and United Good Neighbors.

Bob Pallari, age 26, Multnomah County Health Department. Mr. Pallari left the Multnomah County Health Department in 
Association.

Individual objectives were also formulated and it was determined that it would be the responsibility of each of the above committees to:

(1) Review recommendations appropriate to each committee; (2) Develop priorities for implementation: (3) Develop strategies for implementation; (4) Develop a time schedule, including total time required and projected completion dates; (5) Cost to the agency for implementation, if any, and possible souroes of funding to defray such costs.

The new Task Force was thus initiated but I had a strange feeling that this new group did not intend to work as prodigiously as the previous one had worked. I did not understand why, but possibly it was because first meetings are always so inhibiting and the new members did not feel as comfortable as I did, a veteran. Regardiess, I did not see much enthusiasm from the existing members either. I knew why the new members were asked to serve, but it is interesting to see why they thought they were appointed. From the seven responses of this second group, five attributed their appointment to their occupation, which is part of the reason, basically, why they were appointed. The other two members, the planning and finance manager, and the labor representative, really did not know. However, the manager thought it was because of his involvement in youth programs and the labor representative felt her interest in the community was the reason for her appoint- 
ment. Actually, they all assessed their selection correctIy because they were appointed because of their occupational role but also because of their activity in the community. The Task Force needed a well diversified occupational base coupled with community-active involvement.

In response to the question whether any of these participants had any individual goals to pursue, the group basically replied "no," just as the former Task Force had replied. The only positive responses stated they desired a better public awareness of venereal disease. After this second group denied any personal goals, I realized that I was not perceptive as to why all these people accepted their appointments. I felt surely that they all would possess personal goals, but I was wrong. I did notice, however, that the few whom at least had the personal goal to see public awareness of venereal disease increased, were among the most active on the committee. I have always felt that personal goals are motivating. Without any personal goals, it is interesting now to peruse their answers as to why they chose to serve on the Task Force. Other than the nurse who stated that it was a challenge, all other responses indicated that the subject matter of venereal disease itself enticed them. The clinical psychologist was attracted by the topic and felt the application of her professional training would be helpful. Venereal disease in the teenage population concerned the legislator, while venereal disease in the 
schools alarmed the Parent-Teacher Association president. The others were generally upset with the alarming rate of venereal disease incidence and chose to serve to help fight it. That the binding factor of the topic venereal disease itself motivated them to join the Task Force differs from the first group of members in that the former group joined either for the privilege and/or prestige of serving on the committee or for a special interest. However, those who had served on the initial Task Force and again on the second one basically kept their original reasons as to why they chose to again serve. Undisputably, the significance of each members participation was reflected when asked what their role had been during the period of the Task Force. The response to this question immediately removed all but six members from the actual accomplishments list of participants. (This does not include the consultants because as in the original group, they were helpful all of the time.) Without exception, all but those six active members who even bothered to respond to the questionnaire stated that their role was simply to attend meetings and/or add input. of course, much of this input was valuable, but the real footwork and action was completed by six members and the ever willing consultants. Additional credit that may be given these non-active members may include the influence they had with legislators, media, or other groups to which they belonged encouraging 
these groups to understand the problems of venereal disease. However, there is no doubt that the six active members were responsible for most of the group's accomplishments. The remainder either lacked interest or did not have the time.

Another interesting point is that out of this six, four were hold-overs from the original Task Force. Therefore, just two out of the eleven who were appointed and accepted with the realization of exactly what was expected of them, and exactly what kind of goals were to be attained, actually contributed to the satisfaction of these goals. From this group of six, only two members pursued their tasks through their individual occupational status. This fact greatly differs from the wider involvement of the preceding Task Force, where virtually all the participation centered around the individual occupation of the members. The nurse, for example, diversified her involvement greatly during the second Task Force. She worked with media, taught venereal disease to school children, participated in venereal disease workshops, appeared on television discussing venereal disease, and worked with various other committees to expose the problems of venereal disease. The venereal disease educator worked with the media to secure public service spots. The stockbroker worked with the community colleges throughout the state in an attempt to encourage venereal disease education both to the students and as courses in their education depart- 
ment to teach future health teachers about the nature and problems of venereal disease. I was the chairman of the legislative sub-committee and I worked with legislators and the executive department to encourage passage of certain related pieces of legislation and secure funding for specific projects (detailed next section). My role during this period actually supplemented my original role with media. I never subsided my efforts for better community education through the media channels. Actually, there probably was not a single member who pursued activities for this Task Force more than I did. Surely, I had less influence in the community than many of the other members, but my contribution was in hours spent pursuing goals for the various projects. One of the members who used their occupation as a basis of their involvement was the Parent-Teacher Association president who made surveys of schools to see what resources they had and were using, and made recommendations to Intermediate Education Districts for better venereal disease curriculum. The other was the legislator (Rieke, as opposed to Hampton of the first group) who persevered in the legislature pursuing passage of several bills.

In regard to the occupational status of the members, an interesting observation might be established. The observation relates to the means and methods as to how each member individually pursued his/her role on the Task Force. The members of the previous group simply did 
not use the resources that I thought they would use to effectuate the goals they envisioned. Instead, their means and methods simply included: (1) Frequent attendance at meetings, (2) Speaking when they felt they had something to suggest, (3) Correspondence, (4) Distribute information, (5) Using consultants as speakers, (6) Time. However, the results of this question evinced entirely different responses from the second group. The legislator arranged to have bills properly drafted, testified at hearings, monitored progress of legislation, assisted Task Force lobbyists and other citizen witnesses, and carried legislation to the floor. The nurse drove all over the state speaking to various oregon Medical Association chapters, telephoned the participants of the workshops to support their teachers at the schools, and performed huge amounts of mailing to promote the workshops. The MuItnomah County venereal disease educator (not the consultant, but the member) made many contacts with businesses, schools, and the media to urge educational programs. The Parent-Teacher Association president wrote articles in several newsletters, appeared on several television and radio interviews, and acquired material from several other states for comparative purposes of Oregon's program. The planning/finance manager made several appearances in front of various legislative committees relevant to venereal disease bills, and personally contacted and corresponded with various organiza- 
tions promoting venereal disease education within those organizations. The judge contacted the American Social Health Association for assistance in our efforts and also contacted several medical doctors in the Portland and Salem areas encouraging them to report cases of venereal disease, rather than destroying the records. My efforts were largely diverse; however, my major contributions were my success with the media in carrying the venereal disease story throughout the state, and with the legislature ensuring passage of related bills.

The difference between the two groups is profound. The latter group pursued activities with an extreme amount of vigor whereas the first group barely moved outside the scope of their own occupation--which is precisely the interesting observation to which I referred. The initial members were influential and helpful in promoting their individual tasks, but their efforts basically remained within the sphere of their occupation. The second group, however, intensified their roles and transcended their occupations to include the entire community. This is exactly why the responses to this question present such extreme differences. The latter group simply used every resource possible to assist their intentions while the original group did not. It must be remembered here that the purposes of each group were different, which could explain the differences between the two groups. The original Task Force was appointed with the ultimate goal 
of preparing the report. All activity in the field of prevention and/or education was ancillary, although much was accomplished. The second Task Force was to fulfill the recommendations suggested by the first one. Therefore, the tasks themselves were consummated properiy, although it has been interesting to see why it happened the way it did. Thus, my apprehension that this second group was not too motivated or concerned enough about the venereal disease probiem was unwarranted.

The second Task Force proceeded effectively through December 1974. Although our staff member was funded through May 1975, the momentum and participation by the members subsided after Christmas of that year. In early 1975 the only activity was assisting the legislative sub-committee capture the necessary votes of the legislators to support the various bills drafted on their behalf. There were three meetings in 1975, one each in January, March, and May, and they were poorly attended. The meetings in January and March were virtually totally oriented towards the legislative bills, and the meeting in May was mainly to terminate the project. The Governor's Task Force on Venereal Disease was officially terminated May $8,1975$. 


\section{IV}

\section{OVERCOMING THE PROBLEM}

Probably the best way to determine an active group's effectiveness is to review its accomplishments. It is truly the only tangible means to measure its success. While many groups may struggle arduously, its effect cannot be truly measured without some kind of track record. Oftentimes, it is difficult to depict success because of the nature of success itself. If a committee were established to raise a specific amount of money towards some goal and it was attained, then the project was an undisputed success. If a committee were established to elect a person to office and the person was elected, then the campaign was a success. But if a committee were established to innundate the public with information on cancer in an attempt to relieve the increasing death rates, what terms would be deemed a success?' Certainly it could not be said the project was unsuccessful if the cancer rates continued to rise, as rising rates does not mean less people were aware of danger signs. Thus, the term success can reflect various meanings, many being abstract. When the Governor's Task Force on Venereal Disease was formed, there were basically two goals that were established. The first goal was one of long range with no 
time frame: Reduce the incidence of venereal disease among young people $(0-25$ years $)$ in oregon. The second goal was to prepare and present to the Governor's Commission on Youth a final report of the Venereal Disease Task Force which would accumulate and examine information and data on which to base recommendations, etc. This latter goal had a specific project upon which when completed would successfully accomplish the intended goal. However, the first goal is such that it would be extremely difficult to assess whether or not there was, indeed, success. Possibly the most tangible assessment of the success of the first goal could be made by relating the "successful" accomplishments of the initial Task Force as related to the overall goal:

(1) Iegislation. The initial Task Force was significantly responsible for the passage of two classic bills in venereal disease related legislation. One of which was Senate Bill 882 which appropriated $\$ 50,000.00$ out of the general fund to be expended for twenty-three two day workshops around the state. These workshops were to be attended by anyone in the community who wished to participate. Basically, teachers, students, and parents were involved. The workshops proved to be a tremendous success with the participants overwhelmingly acknowledging a better understanding of venereal disease. The workshops were held all over the state and prompted community demand for effective venereal disease education programs for stu- 
dents and adults. Additionally, and more importantly, the bill states that no teacher shall be subject to discipline or removal for teaching or refusing to teach venereal disease education. The importance of the sentence above cannot be overemphasized because for the first time in Oregon's history can a teacher instruct students without fear of reprimand or even termination from the school. Heretofore, many educators were fearful of venereal disease education because the principal, school board, or parents either would not allow it or did not support it. The apprehension was lifted with the passage of Senate Bill 883.

A third bill was also passed in the 1973 legislature but before the origination of the Task Force. This bill, Senate Bill 25, allowed condoms to be sold in the vending machines which made them more publicly accessible.

(2) Legislator Awareness. The constant lobbying and pressure applied to the legislators encouraged a better understanding and awareness of venereal disease and related issues. This better understanding would assist passage of additional bills in the 1975 legislature.

(3) Executive Office Awareness and Commitment. Through communication and feedback to the office that created the Task Force, the Governor and staff became greatly more aware of venereal disease problems. More importantly, they became committed to assist the Task Force and helped it overcome legislative hurdles both in 1973 and 
1975. Letters signed by the Governor helped open doors at various educational institutions, the media, and civic organizations.

(4) Workshops. As mentioned above, the workshops were highly visible and successful. They created interest and discussion and led to a better understanding in the various communities around the state. In addition, the workshops stressed non-judgmental training to eliminate the moral issue. They alerted teachers to instruct venereal disease education from a clinical point of view, rather than a moral one.

(5) Medical Profession. Through contacts at the Oregon Medical Association, guest speakers representing the Task Force strongly encouraged physicians to read current information on venereal disease (a surprisingly high number of physicians are unaware of the extent venereal disease has become epidemic). Additionally, the physicians were requested to report all cases so epidemiological research could ultimately stop the chain of infection. Doctors probably report only about 20 percent of the cases they treat, although it is required by state law.

(6) Contact with Gay Community. One of the highest groups to contact syphilis has been the gay community. One of the Task Force members, an admitted homosexual, had constant communication with the gay community. Many gays felt that they could not catch a venereal disease 
from those of the same sex. Moreover, many of the gays are "closet" gays and are afraid to seek medical help for fear their homosexuality would be exposed. This contact with these people was one that had been unsuccessful prior to this time.

(7) Sex Education. One of the underlying reasons that parents have been so adverse to venereal disease education is they confused it with sex education. In communication with educators, Perent-Teacher Associations, legislators, and others, the Task Force members repeatedly indicated that this was not so. A better understanding of the actual purpose of venereal disease education helped others accept it much more readily.

(8) Media. Co-operation from the media surpassed all expectations. Virtually all television stations in the Portland area, several radio stations, and the newspapers were unabatedly willing to assist. The television and radio stations provided constant public service announcements and donated air time for several talk shops. "The Oregonian," "Oregon Journal," and several neighborhood newspapers released articles alluding to the venereal disease problem. These methods of communication reached nearly everyone in the entire state.

(9) Overall Awareness. The eight accomplishments listed above all relate directly to one important accomplishment--overall awareness. Awareness and recognition of the problem has been the major obstacle in the fight 
against venereal disease. Uneducated ideas and ignorance of venereal disease has severely inhibited educational methods aimed at extermination of the disease. The above eight vehicles were methods of reaching all types of people in a relentless effort to give them a better understanding. Overall awareness could not have done otherwise than to have been significantly affected because of the vast amount of exposure the venereal diseases were given during this period.

So, was this long range goal initiated by the Task Force successful? Not directly. But the knowledge evinced from the efforts of the Task Force, I am sure, will someday directly effect the goal of reducing venereal disease.

Was the second goal successful? Very definitely. The report was completed and presented to the Governor. It was so successful that its recommendations were the basis for the second Task Force. Notwithstanding, the National Center for Disease Control recognized it to be the most effective report on venereal disease of all studies done by any citizen task force.

All the members of the initial Task Force responded quite positively when asked if they felt the Task Force, as a whole, had been successful. When asked what they themselves had accomplished, all but two responded with favorable reports. All but two members felt that they had personally accomplished something by serving. The 
exact responses did not follow any pattern, but it is interesting that these participants were able to get something out of their participation as well as what they contributed to make it successful.

The second Task Force also had its accomplishments but not exactly of the same kind. Since several of the members had served on the prior Task Force, they merely continued working on the projects with which they had been involved originally. The newer members fell into place basically under the original members' direction. Although the purpose of the second Task Force was to pursue the recommendations of the initial group, no pattern was ever followed in that direction. However, any accomplishment was within the realm of alerting the public or the eradication of venereal disease, so all activity was germane. The accomplishments include: $f(1)$ Legislation. Four major bills were drafted and introduced in the 1975 legislature with much of the substantive portions coming directly from the Task Force. House Bill 2822 supported the sale of condoms in places other than pharmacies and vending machines which allowed any retail store to sell them. (There has always been apprehension from people in purchasing condoms, which is the most effective safeguard against venereal disease other than abstention. The purpose of this bill was to make it even easier to purchase them.) This bill was passed easily by both houses. A second bill, senate Blll 609, 
dealt with confidentiality of venereal disease records. The bill provided that without the defendant's permission, no medical venereal disease records would be subject to subpoena in a civil suit. The main purpose of this bill is to protect the parties in a divorce case where venereal disease is not a substantive issue. It also releases inhibitions for those fearful of exposure to seek medical help. This bill was also approved. A third bill, House Bill 3074, would have permitted minors under twelve years to be treated for venereal disease without their parents permission. This bill was defeated because it was felt that parents should be alerted to the fact if their child were being molested or engaging in any sexual activity at that age. The present law allows confidential venereal disease treatment for anyone twelve years or over. A fourth bill, House Bill 5021, provided for five new positions in the state for epidemiologists. The dollar appropriation for the biennium was to exceed $\$ 100,000.00$ and it was difficult convincing the budget analysts of its importance. Initially the money was to be provided by the federal government if the Congressional bill were approved. The purpose of this bill in the oregon legislature was to guarantee the funding if the federal money were not approved. The legislature passed this bill; however, it was not needed as the federal money was approved and the positions granted.

(2) Speakers Bureau. The second Task Force created 
a speakers bureau through the assistance of some of the consultants. The speakers would request time with various organizations and delivered venereal disease information. Oftentimes, the speakers would be approached for speaking engagements, rather than search for accepting organizations.

(3) Service clubs. A large number of service clubs, auxiliaries, and social clubs were approached requesting time to speak on the topic of venereal disease. The speakers of the speakers bureau would then pursue the speaking engagement. This successful project was accepted well with these kinds of clubs.

(4) Frisbees. The Task Force initiated a frisbee project that was funded through the Jaycees. I personally originated the project that would help give exposure to the venereal disease problem and raise money for venereal disease educational materials for the local schools. Approximately 10,000 frisbees were sold around the state in nine communities. The media assisted to a great extent for this project.

(5) Educational Services Report. The Task Force investigated and created a report assessing the venereal disease educational services and programs in oregon. This report, in turn, helped determine which areas needed better and more extensive programs. With the help of the State Department of Education, better programming was pursued. 
(6) Steambaths. One of the more concentrated areas of homosexual gatherings are in the steambaths. The member representing the gay community was able to convince those attending the steambaths of the sincerity of the venereal disease epidemiologists and venereal disease tests were soon being administered at selected steambaths in Portland. This innovation was tremendously helpful in isolating syphilis among homosexuals.

(7) Commitment of Prestigious People. This is an area where the contrast significantly developed between the two task forces. Whereas the first Task Force was quite effective in originating projects and increasing awareness, the second group was most effective by means of the prestigious contacts that helped effectuate change. The first group used their occupational status to initiate projects and develop a modis operandi, the second group used less footwork and more contacts to pursue projects. The establishment of various commitments and the determination of instrumental people in the community allowed not only the advent of the above projects, but additionally, the continuation and expansion of the accomplishments of the prior group.

This second group, similar to the first, felt that the projects and time spent on the Task Force was beneficial and worthwhile. Many were gratified as a result of the time spent on their individual or group projects. Humars are political animals. The inter-relationships 
between them are most significant in our progressive society. To evaluate their behavior in a political setting is an interesting aspect of a case study. The next, and final section, will attempt to do just that. The analysis of their prestige and influences in the community as it related to the Governor's Venereal Disease Task Force will conclude this study. 
EVALUATION

This study has attempted thus far to survey and analyze a volunteer group that was chosen in an effort to accomplish specific goals. The basic problem, that of venereal disease itself, was defined and explained in the first section. The second section discussed the origin and organization of a group of citizens who were chosen to alleviate this problem. The third section related the goals, projects, and personalities of the original and final task forces. These sections also analyzed the individual and his role on the Task Force in an effort to see why that individual was serving and what input he contributed. The fourth section listed the accomplishments and made an effort in assessing the entire function to determine whether or not the entire task was worthwhile.

This section, however, will attempt to explain just why the group was able to enjoy its accomplishments and possibly how it did so. Basically, this section will review whether it was influence or arduous perseverance that allowed them to complete as many projects as they completed, and made such an impact on the community. Webster defines "influence" as energy or potency 
tending to produce effects insensibly and invisibly; power arising from character or station; directing power based on moral or social superiority. 3 James Robinson, author of Congress and Foreign Policy-Making, wrote "Measuring influence is a combination or gauging the degree of participation in making decisions, the scope of value affected by those decisions, and the extent of the consequences of and the number of persors affected by the decisions."4 To determine whether or not any of the members of the Venereal Disease Task Force had influence would depend whether or not their effects upon the community could apply within the general realm of Webster's or Robinson's definition. Did the group have energy or potency which produced effects? Did the group have power? Did the group have superiority over others which caused effect or change?

Based upon the accomplishments already established, I would say yes, the Task Force did exert influence over others to accomplish its goals. The effect on the legislature, the Governor's office, the media, education, and many, many organizations show certain energy or potency which produced results. What might be more convincing, however, would be to observe the response from the members themselves as to whether they feel that they influenced

${ }^{3}$ Webster's New Collegiate Dictionary, G. and C. Merriam

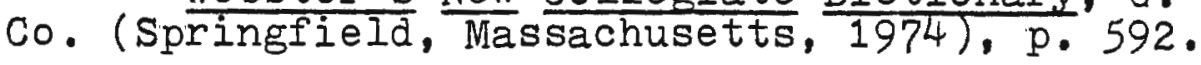

4 James Robinson, Congress and Foreign Policy-Making, (Homewood: The Dorsey Press, 1962), p. 13. 
others in obtaining their accomplishments. Moreover, it is interesting to review their responses as to whether they felt that it was their prestige in the community that helped them influence others.

Reviewing the first group, an interesting observation is that those who admitted that their prestige and influence in the community and those who denied it were split between the members and the consultants. While every member recognized that his/her influence was a major factor in effecting change, only two of the consultants felt their influence was significant. One of these two consultants stated that his membership on the Board of Directors of the Tri-County Community Council determined his influence in his accomplishments, which would classify him more as a member than a consultant (this reasoning because he belonged to an influential group which could assist his goals as did the members). The other consultant responding positively in this area was the public administrator of Health and Social Services for the state of Oregon which had already shown leadership with venereal disease control. Because of his influence with previous groups attempting to eradicate venereal disease, he was again able to procure their help for the Task Force projects. Thus, these two consultants had viable organizations from which to base their projects which in turn enabled them to enjoy influence with others. As was mentioned above, all members responding felt 
their prestige and influence in the community helped them in obtaining their goals. The judge, for example, was a director of the American Social Health Association, which enabled him to get staff, ideas, and support. The assistant director of the Oregon State University Extension Service exerted his influence on the state Department of Education to initiate programs. The representative from the gay community was able to establish respect and a line of communication between his group and the health department. The college president used his status with the Board of Education. The physician president of the Oregon Medical Association used his credibility with other physicians in an effort to encourage physicians to report venereal disease and help advise the public of its consequences. The secondary school principal stated that his leadership role in administrative educational circles allowed him to communicate with other educators on a broad base and helped initiate better venereal disease programs in the schools. The attorney/legislator acquired the support of other legislators to contribute towards the passage of new, more liberal venereal disease-oriented laws. The Parent-Teacher Association president used her position to convince parents around the state of the urgent need of venereal disease education and encouraged the same parents to promote programs at their local schools. The nurse, who belonged to a very large number of organizations, made good use of these organizations to pass through awareness 
of venereal disease problems and use them as a base to reach others. I was able to use my resources with the media and individual legislators toward specific goals. Each member used the group or groups of people with which each was associated to assist them. The second Task Force revealed the same thing, although much less so. Equally important is the fact that these community influentials (especially the second group) contacted other people not on the Task Force that had influence in the community, as well. Listed below are the general groups of people or organizations that were utilized to promote the Task Force projects:

(1) Legislators

(2) Parent-Teacher Association

(3) Medical Auxiliary

(4) Dental Auxiliary

(5) Ecumenical Council

(6) School Administrators

(7) Teachers

(8) Television-Radio Media

(9) Newspapers, periodidcals

(10) Home Economists

(11) Association of Health Educators

(12) Law Wives

(13) Lobbyists

(14) Public Health Officers (County level)

(15) Labor Unions 
(16) Businessmen

(17) Lions Club

(18) Oregon Association of Chiropractic Physicians

(19) Jaycees

(20) Optimists

(21) State Board of Education

(22) Tri-County Community Council

(23) American Social Health Association

(24) Oregon Medical Association

(25) Oregon Board of Pharmacy

(26) Governor's office

(27) Department of Education

(28) State Health Department

The entire list above consists of leadership that enjoys enough influence to affect others. But it must be remembered that the Task Force members had to have their own influence to influence the above groups. Without this individual prestige or power, the list of groups would not have been affected. Thus, the Task Force members served more or less as catalysts which in turn prompted the groups to accomplish the desired goals of the Task Force. Moreover, these groups served as the necessary vehicle to affect a large enough population necessary to make an impact on society as a whole.

There have been several studies based upon influences in a community. These studies, among other things, have attempted to depict what kind of individual is most likely 
to achieve influential status. M. Kent Jennings, for example, in his book Community Influentials, examined three types of people who enjoyed cemmunity influence. His types were: (1) economic dominants, which have substantial money but are not too interested in policy making; (2) prescribed influentials, which are basically professionals and highly politicized in their community roles; and (3) attributed influentials, who have the highest combination of social-status and political-status. 5

If Jennings were doing a study on the Venereal Disease Task Force, he would place the membership into his "prescribed influential" category. These people basically all came from social backgrounds typically. associated with the middle class. As Jennings would require of this group, they basically came from moderately successful families, have had some college education, and earn higher than average incomes. Although these peple are generally highly politicized, they could not be considered "attributed influentials" because they are not born of high social status.

The members of the task forces were also not economically powerful. As Robert A. Dahl in his book who Governs depicted, communities show a multiplicity of power centers with the wealthy and corporate executives as only one of

$5_{\mathrm{M}}$. Kent Jennings, Community Influentials, (London: The Free Press of Glencoe, Collier-MacMilian Ltd., 1964), p. 19. 
several kinds of influentials in the community。 6 His study showed that the influence roles of people in government and politics are generally rather prominent. In the Task Force groups, there was participation by all members in some governmental or political function simply by the nature of the Task Force itself, as well as the goals they were attempting to accomplish.

Dahl's concept genereally rebuts Floyd Hunter's arguments on community influence. In his book, Community Power Structure, Hunter essentially stated that a relatively small group of people--primarily big businessmen-exercised general influence on the outcomes of major community problems, projects, and issues. 7 Both Hunter's and Jennings' studies were based on a case study of Atlanta but a wide difference of behavior would probably not be significantly different in any major United States city. Hunter may have felt that a small economically dominant group of businessmen affected much of the outcome of a city, but it certainly could not apply to the Task Force under study here. The Venereal Disease Task Force used the influence of its members which greatly affected the influence on a large number of groups and organizations. This latter influence, in turn, affected the population as a whole. And, none of its members could be described

6 Robert A. Dahl, Who Governs, (New Haven: Yale University Press, 1961, , pp. 89-168.

$7_{\text {Floyd Hunter, Community Power Structure, (Chapel }}$ Hill: The University of North Carolina Press, 1953), pp. 60-113. 
as Hunter has described in his "Regional City Leaders." It must be regarded that Hunter, Dahl, and Jennings are referring to the general leaders of any given place. They described a given city with the policy makers and those who really contribute to the direction of the city. But at the same time, they describe these leaders as those of influence, meaning that these people have the necessary influence in the community to affect others. An analogy could be made to a smaller sub-group of people with similar influence, because the sub-group leaders also need certain influence to affect the general population. This type of definition would apply to the venereal Disease Task Force groups whom also needed this type of influence to cause any impact on the several groups of people and organizations that ultimately influenced the community as a whole, so as to cause a change in policy.

A task force or committee such as this may be considered a sub-community which would have similar features as the leadership of an entire community but on a smaller scale. For example, Hunter has described the structure of community influentials as being "held together by commor interests, mutual obligations, money, habit, delegated responsibilities, and in some cases by coercion and force." 8 Several of these same features are built into the structure of a committee similar to the one under study. 


\section{6}

These variables, coupled together with the status of its members can enjoy enough power to direct an entire community. Students of political science would probably classify the Venereal Disease Task Force as a special interest group. At the same time, however, the Task Force may be classified as a public interest group. David Truman, in his volume The Government Process implied that public interest refers to general or common interests shared by all or substantially all members of the community. 9 Conversely, special interests are shared by only a few people or a fraction of the community and exclude others and may be adverse to them. The reason I feel the Task Force may be considered within both groups is that while the group was definitely involved in a special cause congruent with the interests of each member and the goals of the Task Force itself, their ultimate goal was aimed at a common good. For the purpose of definition, however, the Task Force would have to be defined as a special interest group, dedicated to specific goals.

Several studies have concluded certain characteristics about this type of group. Paul F. Lazarsfield found that those members of society that have influence or political clout had an upper-class bias. ${ }^{10}$ He found overwhelming evidence that participation in voluntary

\footnotetext{
9David Truman, The Government Process, (New York, 1951), pp. 50-51.

10Paul F. Lazarsfield, The People's Choice, (New York: Lazarsfield and Associates, 1951$), \mathrm{p} \cdot 145$.
} 
organizations is related to upper social and economic status. Ira Ried found the same type of class bias of private associations as well. ${ }^{11}$ other studies, however, such as the one conducted by Donald Matthews in 1954, have shown that influentials at various levels have widely disparate social backgrounds. ${ }^{12}$ Robert Doland, author of Dixie City: A Portrait of Political Leadership, confirms Matthews findings. 13 Their findings, associated with those of Iazarsfield and Ried, perfectly depict the typical status of each Task Force member: Upper middle to upper class achieved status but with backgrounds that followed no similar patterns in relationship to one another. The members gained their prestigious role in the community during the course of their careers, but it was independent of their social background.

Actual wealth of the members did not relate to each individual's effectiveness or status during the course of the Task Force. In his book, Community Power structure, Floyd Hunter described the actual leaders of Atlanta being the economic leaders of the city ${ }^{14} \mathrm{M}$. Kent Jennings, in

${ }^{11}$ Ira Ried, "Leadership Selection in the Urban Locality Areas," Public Opinion Quarterly, vol. 14, (1950), pp. $262-284$.

12 Donald R. Matthews, "The Social Background of Decision Makers," Doubleday Short Studies in Political Science, (New York: Doubleday \& Co.., Garden City, 1954), pp. 20-55.

13 Robert Doland, Dixie City: A Portrait of Political Leadership, (Tuscaloosa: University of Alabama Bureau of Public Administration, 1956), pp. 5-17.

14 Hunter, op. cit., p. 81. 
his book Community Influentials opposed this suggestion and stated the economic dominants "are not widely acknowledged to be men of power."15 other studies have shown diverse trends depending upon the city studied, whether it be Edward Banfield's study of influence in Chicago or Carol Thometz's study of influence and decision making in Dallas. ${ }^{16}$ All four of these studies, however, acknowledged that the dollar had clout. As Carol Thometz noted "...the leadership structure reflects the nature of the city's economic structure."1? Referring to the discussion considering the influence of the Task Force members and their influence in the community, only the fact that their generally upper middle to middle class associations could have had a bearing on this issue. No individual alone had the wealth or corporate position that could have influenced the governmental sector, the media, or other business institutions enough to increase effectiveness.

While assessing the influence of a citizen, Nelson W. Polsby, in an essay "Three Problems in the Analysis of Community Power," noted a significant fact. ${ }^{18}$ During the

15 Jennings, op. cit., p. 49.

${ }^{16}$ Edward C. Banfield, Political Influence, (New York: The Free Press, 1961); Carol E. Thometz, The Decision Makers, (Dallas: SMV Press, 1963).

17Thometz, op. cit., p. 31.

18 Nelson W. Polsby, "Three. Problems in the Analysis of Community Power," The Sociological Review, vol. XXIV, (New York, 1959), p. 796 . 
course of his studies, he found that each arena of community problems (politics, public welfare, industrial development) had its own set of influential persons. To assess influence in a given community, synthesization of all arenas and influentials must be completed. If the Task Force members in this study were to attempt an entirely different issue, success may have been impossible. For example, if the same groups were chosen as a task force to inhibit nuclear power in the state, there probably would have been no prestige or status within the group to accomplish the task. Their influence was among others that were helpful because of this issue. Certainly the help of the media and legislature may have been maintained, but how about the clergy, the Parent-Teacher Association, the Department of Education, the gay community, home economists, Tri-County Community Council, or any of the others that were so prominently a part of its success? The essential difference is that the Task Force members were influential within the groups necessary to get the job done.

This observation would be true of any group, and praise for its accomplishments should not be abated. 'But it must be recognized that because the Task Force was successful in its goals with such a multitude of organizations, it does not mean the overall status and influence of its members in the community would place them at a high level of community influence recognized in several 
arenas. However, the roles they played in this effort had a significant impact on institutions and the community as a whole.

"One of the most common patterns of behavior to be observed in American community life is that participation in the making of decisions is concentrated in the hands of a few."19 At the same time, however, this should not suggest that American communities are ruled by a single all-purpose elite. Each interest group has its own cause and its success depends on variables such as the legal channels, institutions, and others that it may utilize to accomplish its goals. If such goals are accomplished, it may very well be a result of the influence exerted upon these variables that precipitated a successful outcome. Quoting James Robinson again:

Measuring influence is a combination of gauging the degree of participation in making decisions, the scope of value affected by those decisions, and the extent of the consequences of and the number of persons affected by the decisions. 20

The degree of influence can differ greatly in a given situation and would have to be identified within the parameters of a given set of circumstances before one could truly measure its impact.

The question asked at the beginning of this section was whether it was influence or arduous perseverance that

$19 \mathrm{Nelson} W$. Polsby, Community Power and Political Theory, (New Haven: Yale University Press, 1963), p. 124. $20_{\text {Robinson, p. } 13 .}$ 
led the Task Force to its successful accomplishments. This question directly relates to the central issue of this case study; that is, the why and how this particular organization was able to take a sensitive problem, organize, and accomplish their established goals. The entire process was a case of a politically appointed group of citizens working through the political structure of society interacting with others. Throughout this study, sections have introduced the reader to the participants of the Governor's Venereal Disease Task Force, as well as depicted their backgrounds. Other sections have shown how each member was able to contribute to the Task Force and the member's inter-relationships with others outside the Task Force who were also instrumental in satisfying overall and individual goals. Still other sections listed accomplishments and related these accomplishments to the members themselves and Task Force objectives.

The combination of these individual sections provide evidence and background which evince an evaluation as to the significance of the political efficacy of the entire group. 'Polity' can be defined as: form of government or a community of persons under a polity. 21 'Political' can be defined as: administration of the polity. 22 The evaluation section of this study has concentrated on the

\footnotetext{
21 Webster's New Collegiate, p. 890.

22 Webster's New Collegiate, p. 890.
} 
more political aspects of this entire study: the administering of a group with homogenous goals with their interaction among others within the polity. This interaction undisputably involved perseverance and diligence to accomplish its goals. But it cannot be denied that had it not been for the influence and esteem held by others for the members by those whose positions would be valuable in the success of specific goals, no amount of hard work could have produced such results.

The evaluation section also introduced several definitions of "influence" and discussed various varieties of thought by many authors. Although the several authors cited did not agree with one another on the general make-up of people with influence, they all did agree that influence of one person or group over another does definitely exist. They also agreed that it is this influence of some over others which is the major policy and decision making process that structures everyday life. It is also agreed that it is influence that enables many special interest groups to accomplish their goals that eventually could affect an entire community.

The evaluation section, furthermore, established that the influence of the members of the Task Force did have enough influence to effectively motivate even more influential people and groups. The question has been answered: Perseverance played an important part in the success of the Task Force, but the accomplishments were a direct re- 
sult of the influence the members exerted over others in the community.

The Task Force concluded its work in the spring of 1975. Upon review of the group itself, it is interesting to note what type of venereal disease education and control is presently occurring in oregon. Upon termination of the Task Force, several community citizens were alerted to the fact that without the Task Force, there would be no viable organization that would assist public health officials in this field. Consequently, another all-volunteer group of citizens in the Portland metropoli$\tan$ area initiated the Tri-County Venereal Disease Action Council to pursue the recommendations of the Task Force. I was appointed chairman in May 1975 and the Action Council has operated several projects in the metropolitan area towards the same kinds of goals. It has been so effective that the American Social Health Association has named it the most successful citizen-volunteer venereal disease organization in the country.

It can easily be declared that the Venereal Disease Action Council is a direct spin-off of the Governor's Task Force and probably never would have been originated without the Task Force as a catalyst. Another accomplishment for the Governor's Task Force.

I would like to mention here that the real cause and effect vehicle to the Task Force accomplishments was not apparent to me during the two year period I was a 
84

member. I was aware of the status of the members but never realized until this study that their community influence proved to be the real vehicle that spelled success. Now that this has been determined, I see the importance and significance of specific types of people serving on committees. At the same time, however, I see the significance of co-ordinating member influence to the subject matter and goals of a given committee or task force as being paramount to success. Committees and commissions have often been criticized for their stagnancy and non-effectiveness and I strongly feel that with this observation considered at the onset, a given group could accomplish considerably more. 


\section{EPILOGUE}

Upon reviewing the Task Force in May 1977, two years after it was terminated, I find additional factors which significantly assisted the efforts of the members. The first factor was the timing. Venereal disease was becoming an enormous problem and its ubiquitous nature was frightening a significant proportion of the population. Consequently, people were willing to listen and assist the Task Force relay the message.

Secondly, I think the political clout of Clay Myers was helpful opening avenues through the executive department and the legislature that possibly would have been closed to the Task Force itself. This is pure speculation, as Mr. Myers' input was not made directly through the Task Force but rather through his own personal channels. However, I do feel that because the group was tagged with Clay Myers' approval, our credibility with the executive department and the legislature was improved.

These two related items were not apparent to me during the course of this study. However, subsequent to deeper analysis of the conditions present during the study, I find them relevant. They were significant, 
86

although not significant enough to alter any conclusions determined in the text. 
QUESTIONNAIRE FOR ALI VENEREAI DISEASE TASK FORCE MENBERS

NAME __ AGE

OCCUPATION SPOUSE'S OCCUPATION

COMMISSIONS AND COMMITTEES SERVED ON IN LAST 10 YEARS:

WHY DO YOU THINK YOU WERE APPOINTED TO VD TASK FORCE?

UPON WHAT SUBCOMMITTEE DID YOU SERVE?

HOW WOULD YOU RATE YOUR PARTICIPATION? 1. NOT TOO MUCH 2. FAIR AMOUNT 3. HEAVY

DID YOU HAVE ANY INDIVIDUAL GOALS ON THE TASK FORCE?

WHY DID YOU CHOOSE TO SERVE ON THE TASK FORCE?

HAD YOU HAD ANY PREVIOUS EXPERIENCE WITH WORK IN VD? IF SO, WHAT?

WHAT DO YOU FEEL THE TASK FORCE ACCOMPLISHED?

WHAT DO YOU FEEL YOUR SUBCOMMITTEE ACCOMPLISHED?

WHAT DO YOU FEEL YOU ACCOMPLISHED? 
TO THE BEST OF YOUR RECOLLECTION, PLEASE TRY AND RELATE WHAT EXACTLY WAS YOUR PERSONAL ROLE ON THE TASK FORCE, i.e., WHAT YOU ACTUALLY DID TO HELP THE TASK FORCE.

WHAT MEANS AND METHODS DID YOU USE TO FULFILI THIS ROLE?

WITHOUT BEING MODEST, DID YOUR PRESTIGE AND INFLUENCE IN THE COMMUNITY HELP YOU IN OBTAINING THESE ACCOMPLISHMENTS? IF SO, HOW? (VERY IMPORTANT)

DID YOU CONTACT OTHER PEOPLE NOT ON THE TASK FORCE

TO HELP YOU THAT HAD INFLUENCE SOMEWHERE? WHO AND HOW?

ANY OTHER COMMENTS THAT YOU WOULD IIKE TO MAKE? 


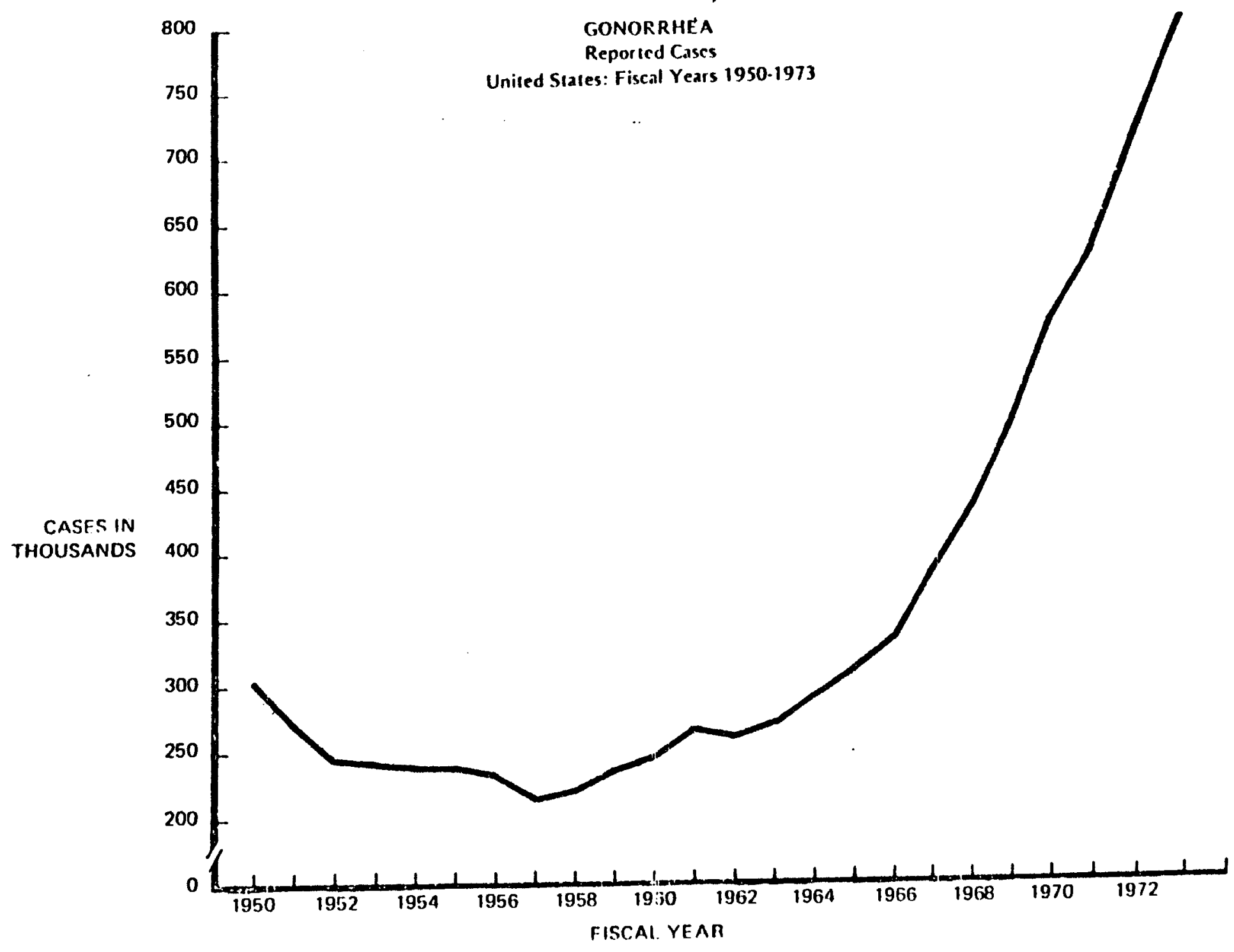


PRIMARY AND SECONDARY SYPHILIS Reported Cases United States: Fiscal Years 1950-1973

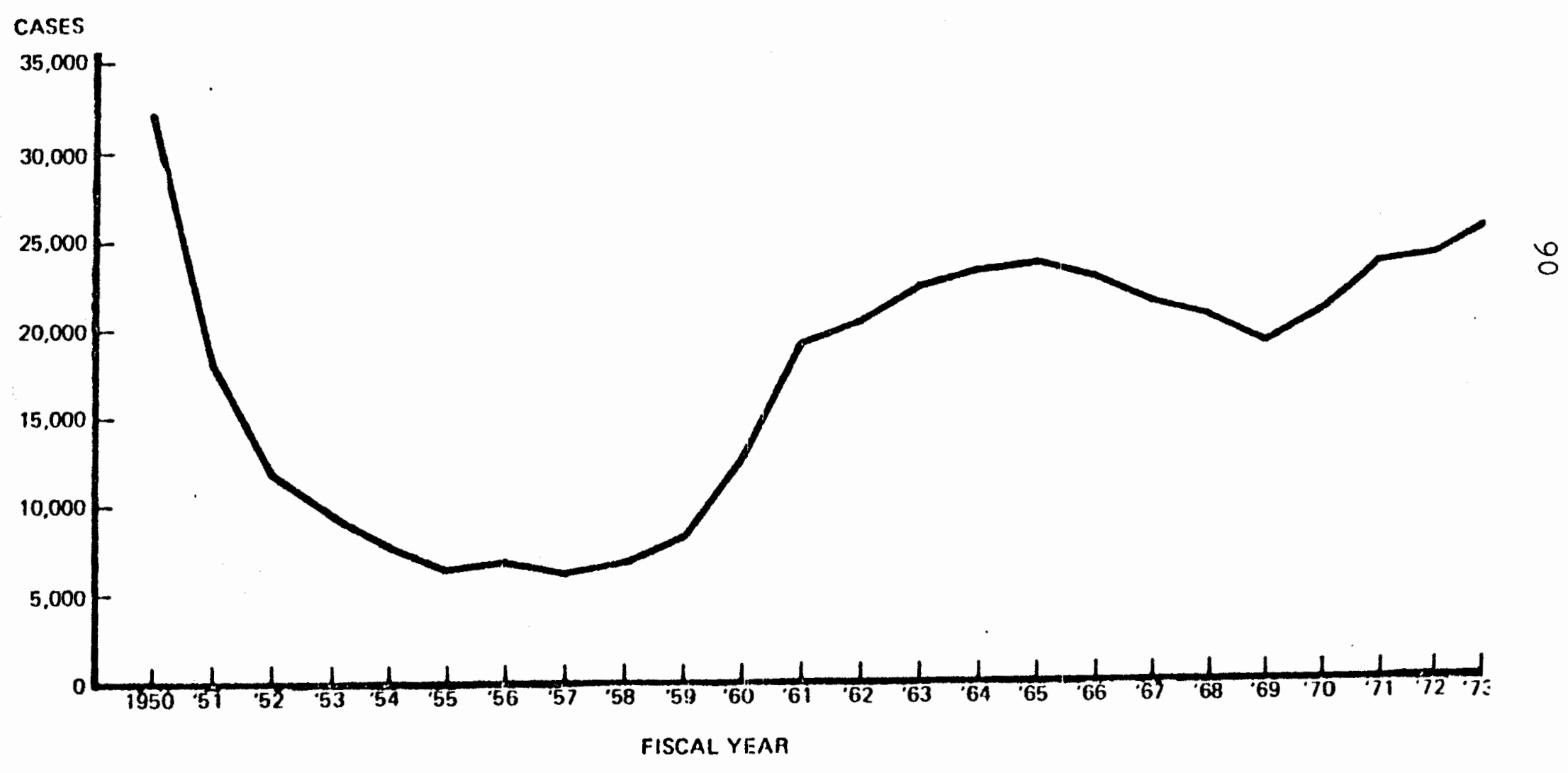




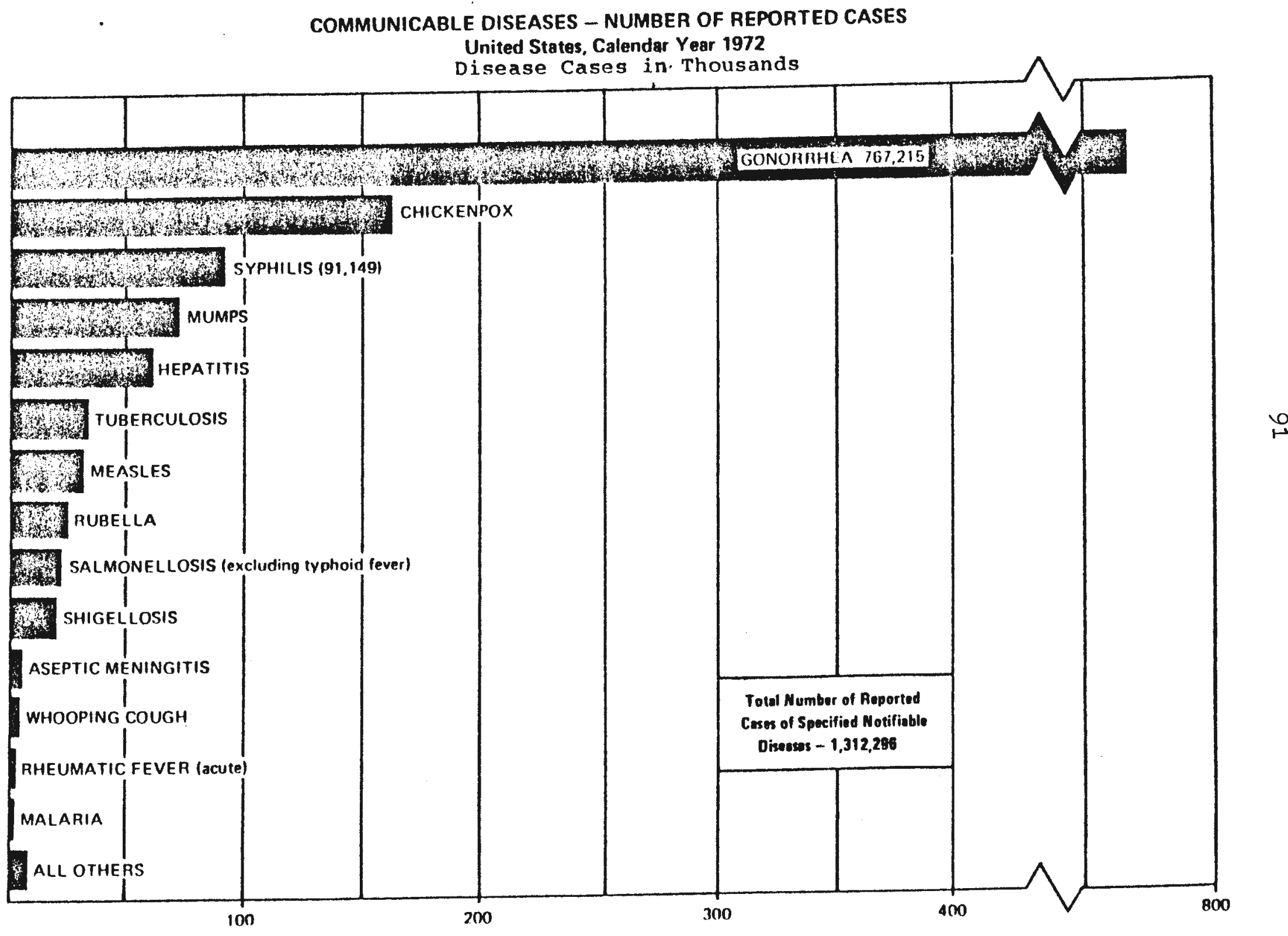




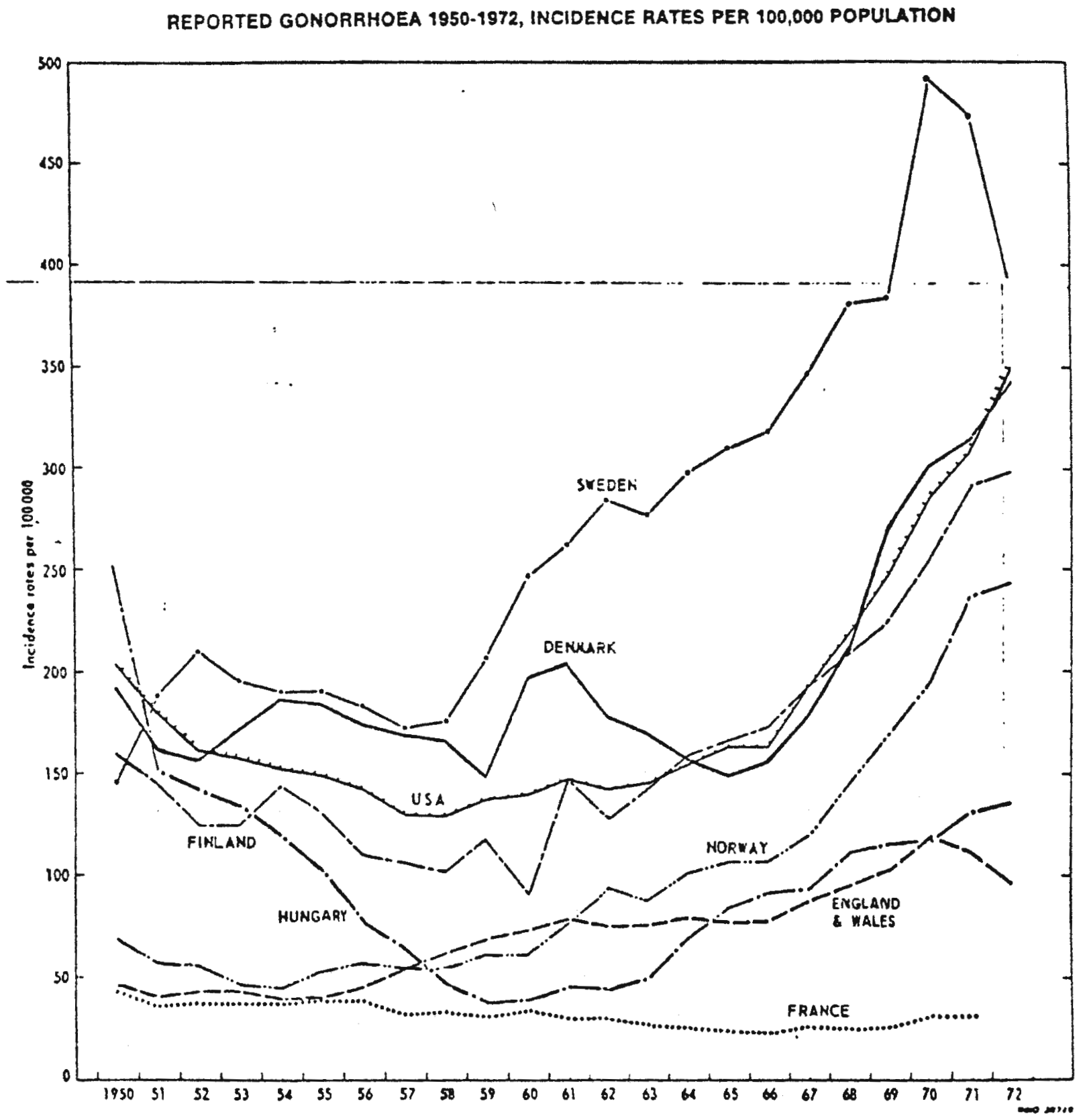


REPORTED PRIMARY AND SECONDARY SYPHIUS 1950-72, INCIDENCE RATES PER 100,000 POPULATION

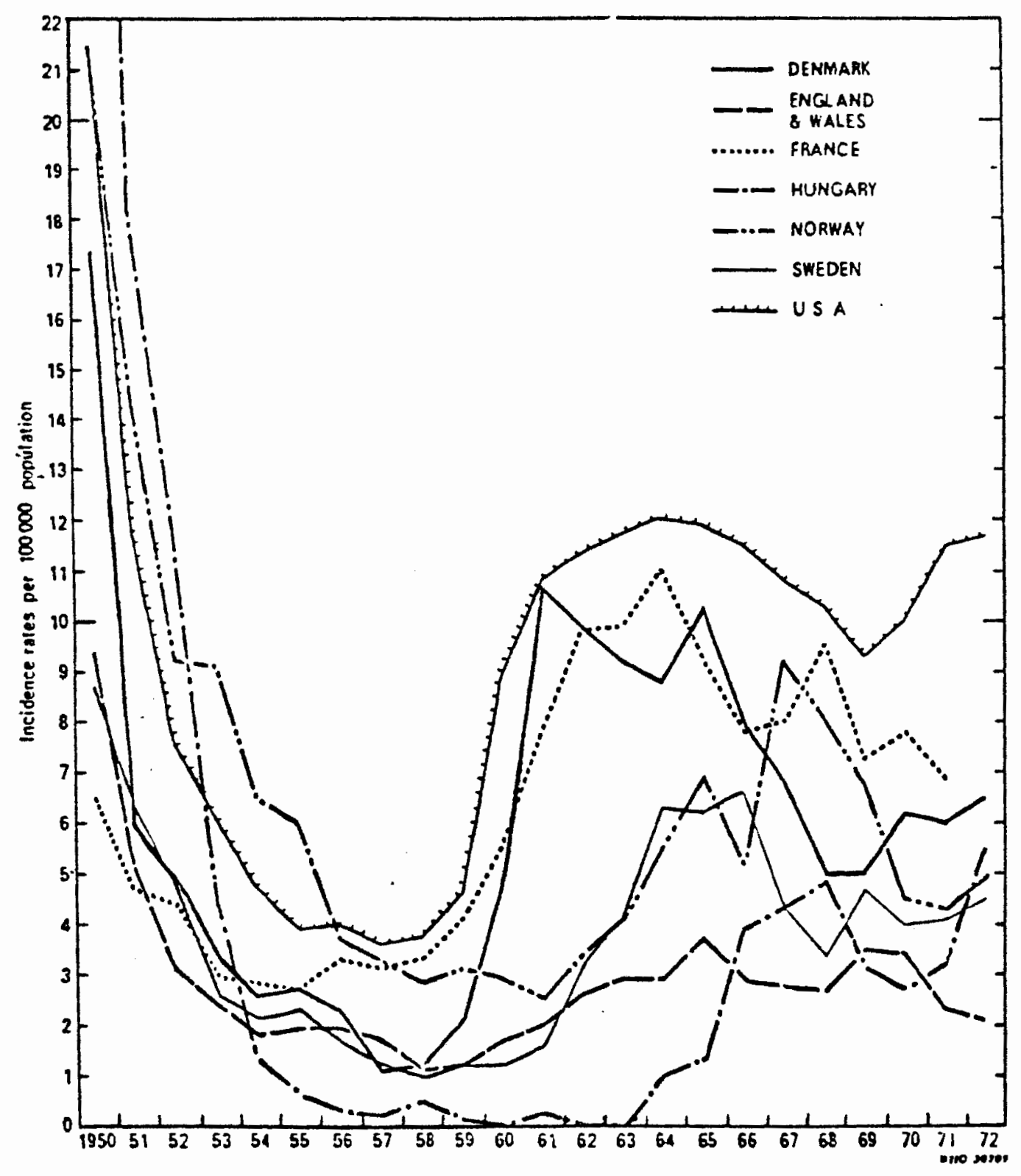




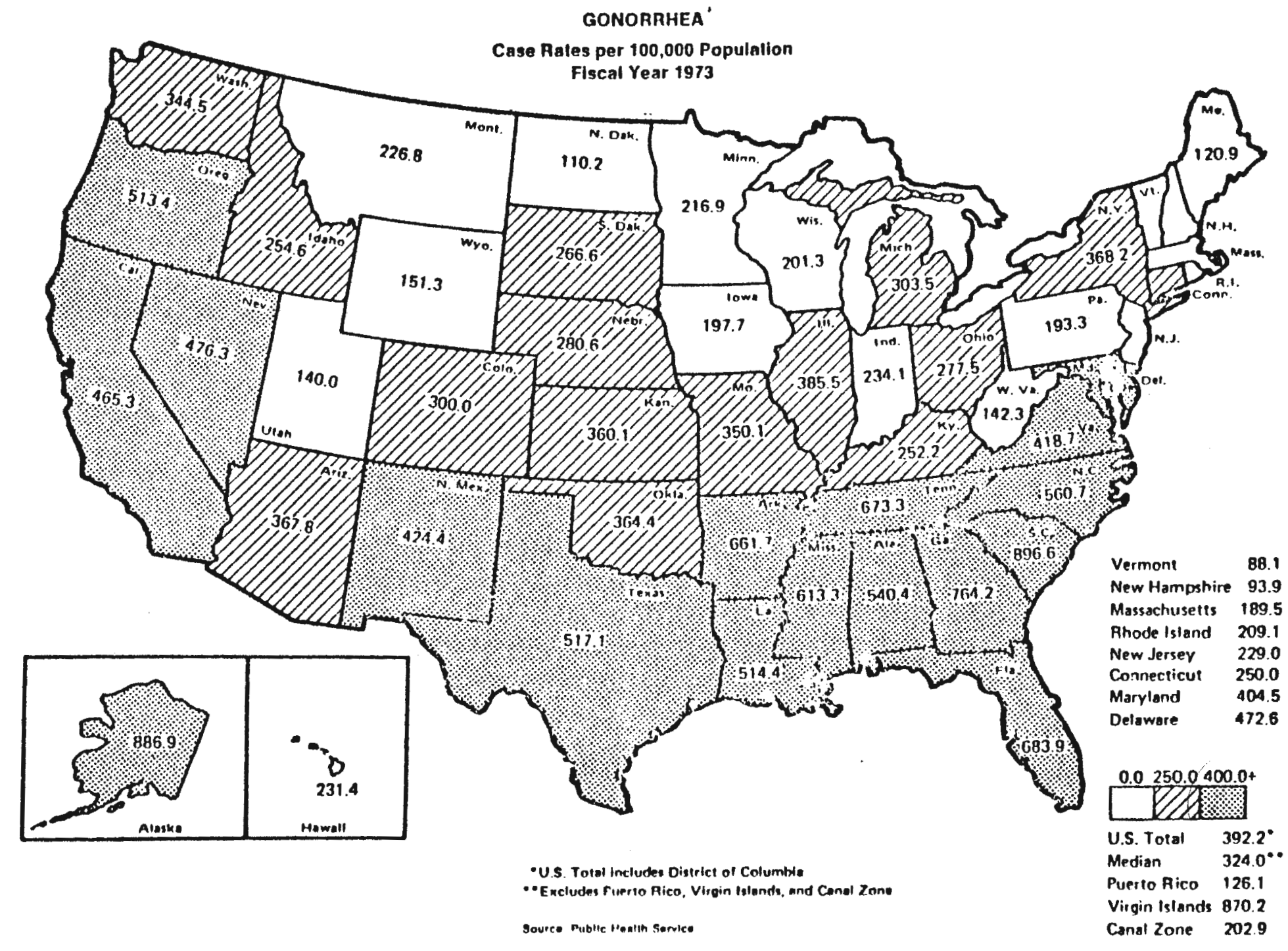


SYPHILIS AND GONORRHEA CASE RATES, OREGON $1940-1973$

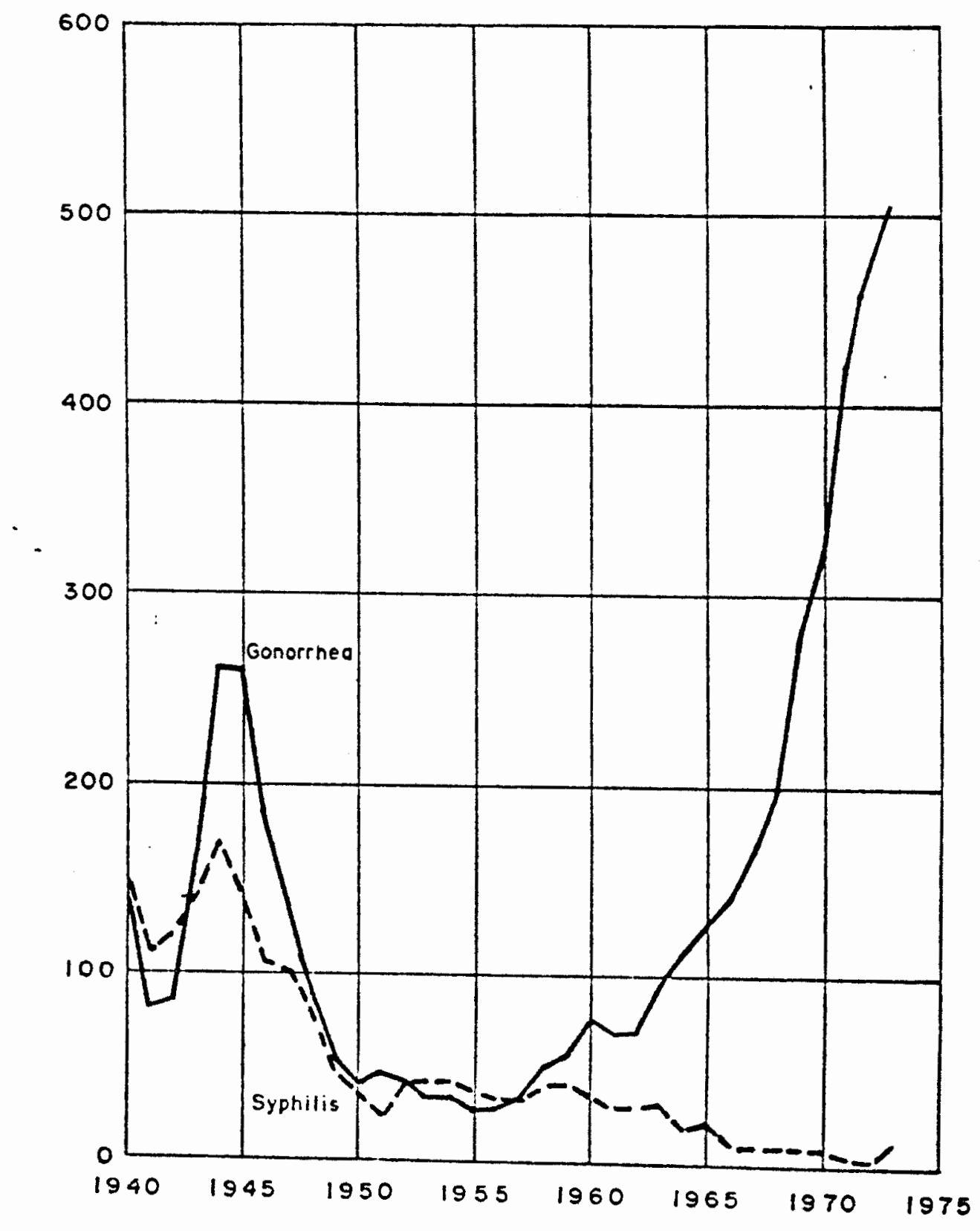


GONORRHEA

Case Rates per 100,000 Population tor State:

Fiscal Year 1973

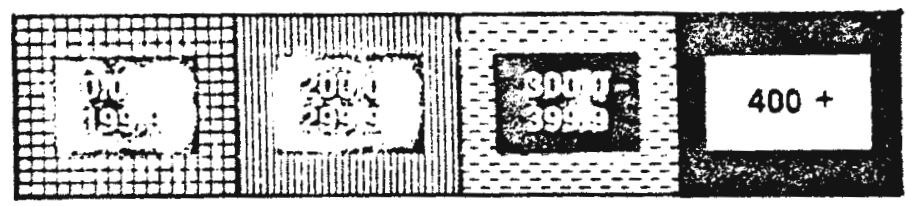

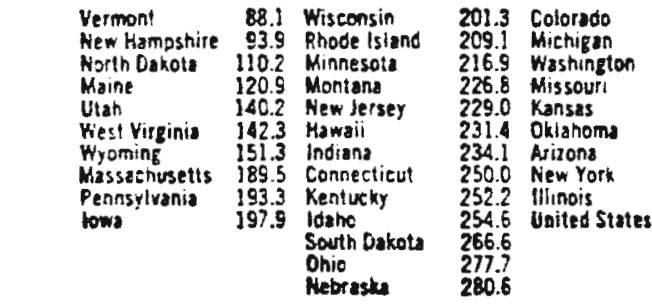

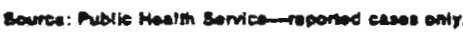

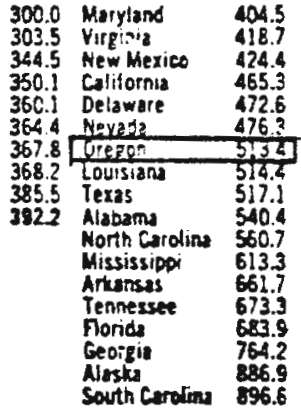

\section{GONORRHEA}

Case Rates per 100,000 Population for 63 United Slates Cities with 200,000 and Over Population

Fiscal Year 1973

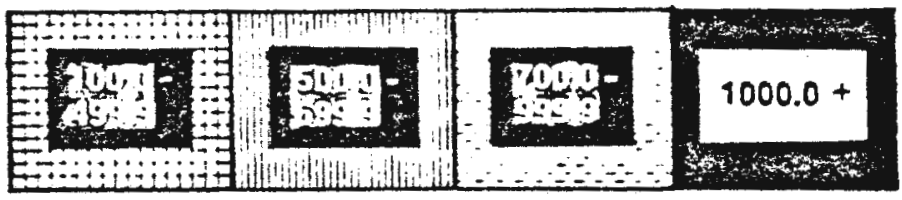

\begin{tabular}{|c|}
\hline 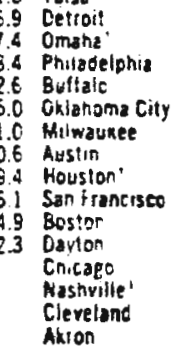 \\
\hline
\end{tabular}

Akion

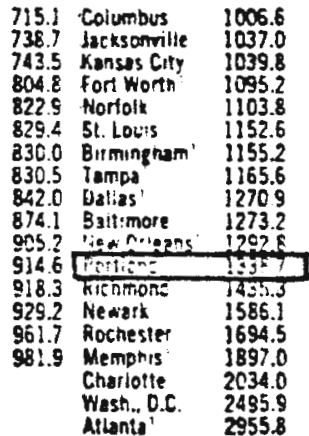

TEquals couniy dals Aretage rate for W U.S cilles: $m$.

Anersoge rate tor US. 2922

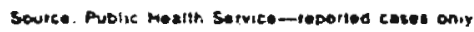




\section{CASE RATES PER 100,000 POPULATION FOR GONORRHEA 15-19 Yoar Ago Group \\ Calendar Year 1972}

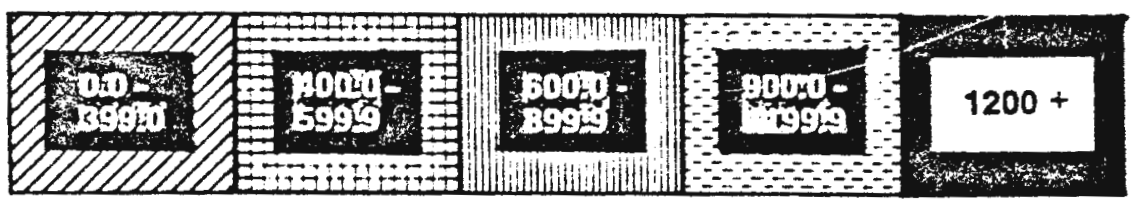

\begin{tabular}{|c|c|c|c|c|}
\hline $\begin{array}{l}\text { New Hampshire } \\
\text { North Dakola } \\
\text { Vermont } \\
\text { Maine } \\
\text { Wyoming }\end{array}$ & $\begin{array}{l}232.9 \\
246.2 \\
269.6 \\
303.2 \\
347.1\end{array}$ & $\begin{array}{l}\text { West Virginis } \\
\text { Utah } \\
\text { Massachusetts } \\
\text { Hawais } \\
\text { Wisconsin } \\
\text { South Uakota } \\
\text { Rhode Isiand } \\
\text { Minnesota } \\
\text { Montana } \\
\text { Pennsyluania } \\
\text { Colorado }\end{array}$ & $\begin{array}{l}405.1 \\
406.5 \\
414.6 \\
40.8 \\
469.3 \\
487.3 \\
488.2 \\
494.8 \\
518.1 \\
521.4 \\
591.2\end{array}$ & $\begin{array}{l}\text { Connetticut } \\
\text { Michigan } \\
\text { Hew dersey } \\
\text { lowa } \\
\text { lndians } \\
\text { Anizong } \\
\text { Washington } \\
\text { Idaho } \\
\text { Kentuehy } \\
\text { Hew York } \\
\text { Ohio }\end{array}$ \\
\hline
\end{tabular}
Colarado

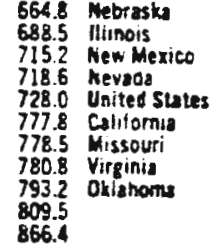

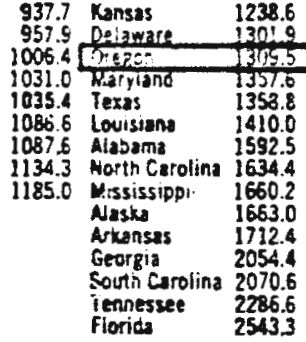

Sourca: Public Hoolth Sameo

\section{CASE RATES PER 100,000 POPULATION FOR GONORRHEA \\ 20-24 Year Age Group \\ Calendar Year 1972}

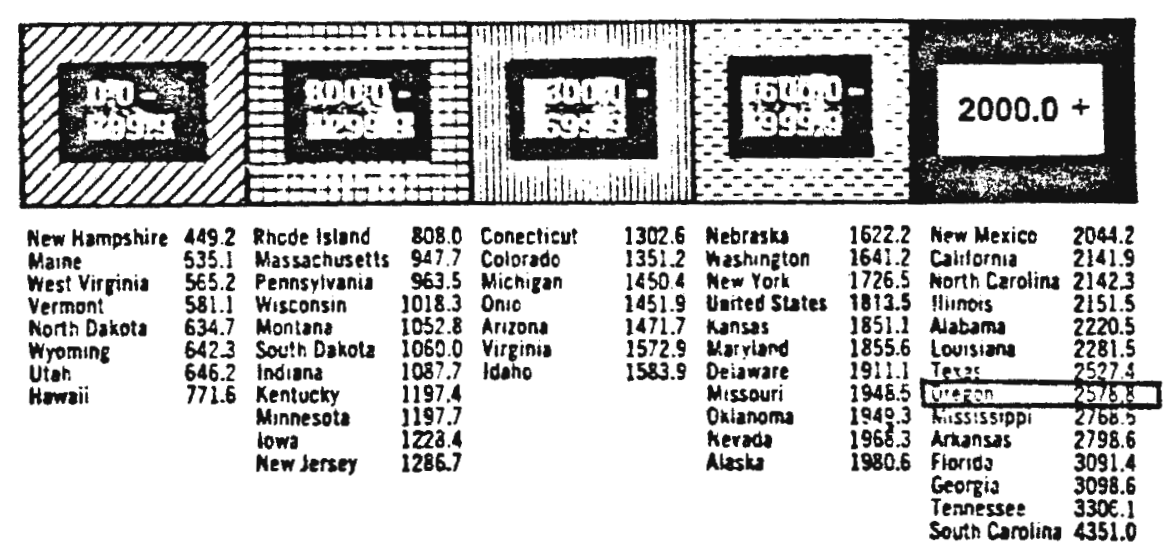

Sourea: Pubtic Houth senves 
STATE OF URES: $\because$

REPORTED VENLRFAL DISEASE STATIETICS

CAIENDAR YFARS $1940-1973$

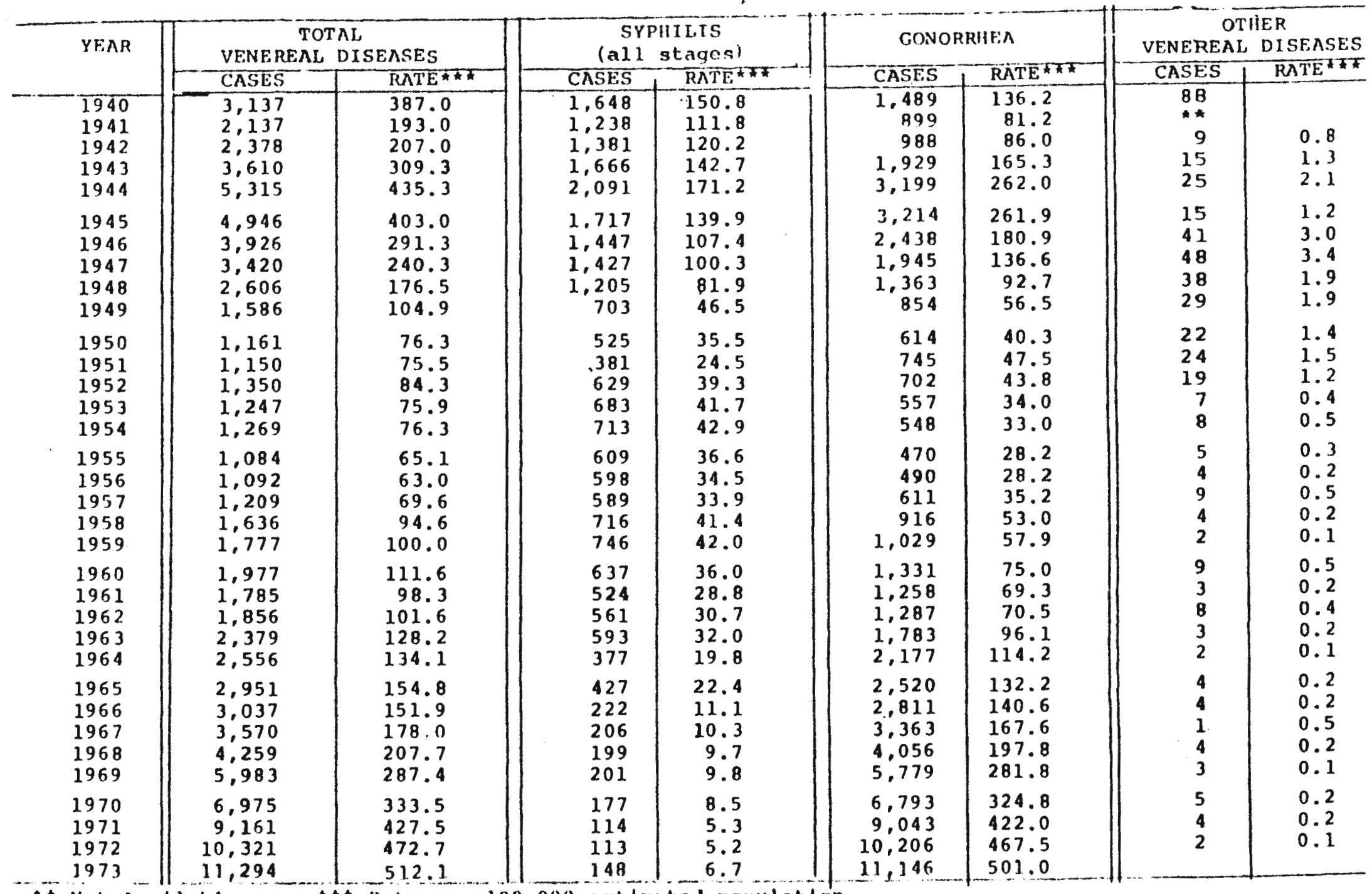


STATE OY OREGON

HEPORTED VENEREAL DISEASE STATISTICS

SPECIFIC NGE + GHOUPS

CALENUAR YEARS 1970-1973

\begin{tabular}{|c|c|c|c|c|c|c|c|c|}
\hline \multirow{3}{*}{ AGE GROUPS } & \multicolumn{4}{|c|}{1970} & \multicolumn{4}{|c|}{1971} \\
\hline & $\begin{array}{c}\text { SYPH } \\
\text { P }\end{array}$ & $\begin{array}{l}\text { ILIS } \\
+S\end{array}$ & GONOF & RRHEA & $\begin{array}{c}\text { SYPl } \\
P\end{array}$ & $\begin{array}{l}\text { ILIS } \\
S\end{array}$ & GON & RHEA \\
\hline & Cases & Percent & Casoa & Percunt & Casug & Percunt & Casey & Pexcent \\
\hline All Ayes & 72 & 100 & 6793 & 100 & $15^{-}$ & 100 & 9043 & 100 \\
\hline inder 10 & & & 9 & 0.1 & & & 15 & 0.2 \\
\hline $50-14$ & & & 47 & 0.7 & & & 77 & 0.8 \\
\hline$I 5-19$ & 3 & 9.4 & 1850 & 27.2 & 3 & 20.0 & 2254 & 25.0 \\
\hline $20=24$ & 9 & 28.1 & 2727 & 40.1 & 4 & 27.0 & 3741 & 81.0 \\
\hline $25-29$ & 9 & 28.1 & 945 & 13.9 & 3 & 20.0 & 1492 & 17.0 \\
\hline $30-34$ & 2 & 6.3 & 404 & 6.0 & 2 & 13.0 & 498 & 6.0 \\
\hline $35-33$ & 5 & 15.6 & 758 & 2.3 & & & 265 & 3.0 \\
\hline 30 and over & 4 & 12.5 & 193 & 2.9 & 3 & 20.0 & 219 & 2.0 \\
\hline Aile Unknown & & & 160 & 6.8 & & & 475 & 5.0 \\
\hline
\end{tabular}

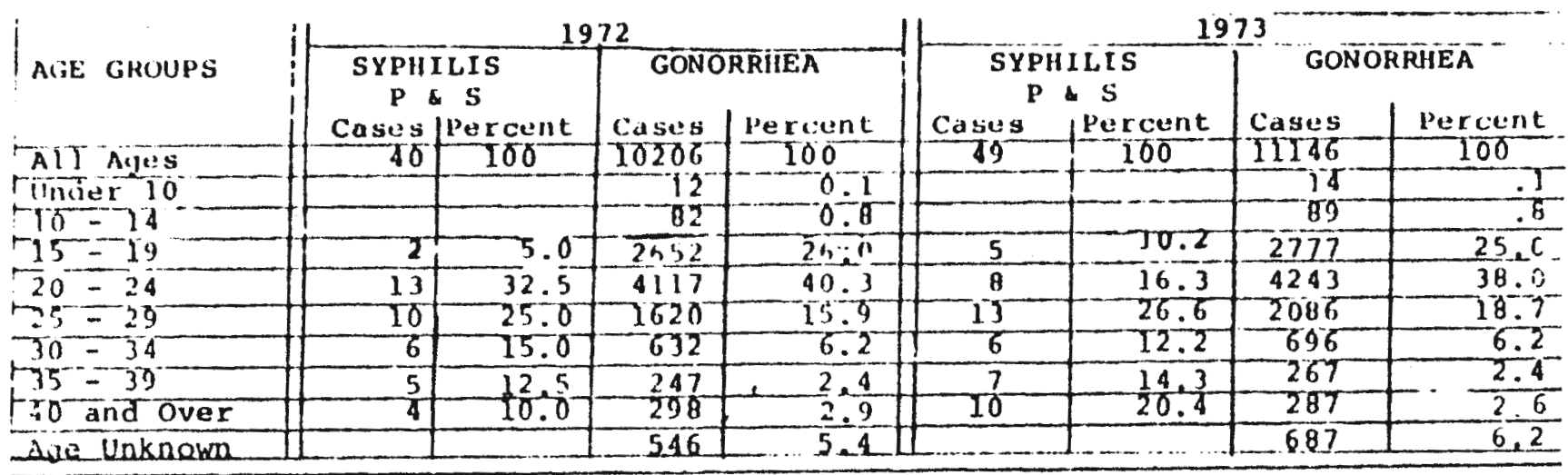


STATE OF OREGON

TOTAI REPORTED GONORRHEA

CASES * RATES

CALENDAR YEAR 1973

\begin{tabular}{|c|c|c|c|c|}
\hline \multicolumn{2}{|c|}{ TOTAL CASES REPORTED } & & \multicolumn{2}{|c|}{ RATES* } \\
\hline $\begin{array}{l}\text { Multnomah } \\
\text { Iane } \\
\text { Marion } \\
\text { Washington } \\
\text { Jackson } \\
\text { Clackamas } \\
\text { Klamath } \\
\text { Clatsop } \\
\text { Iinn } \\
\text { Douglas } \\
\text { Coos } \\
\text { Benton } \\
\text { Umatilla } \\
\text { Polk } \\
\text { Josephine } \\
\text { Deschutes } \\
\text { Lincoln } \\
\text { Wasco } \\
\text { Yamhill } \\
\text { hood Fiver } \\
\text { Union } \\
\text { Jefferson } \\
\text { Columbia } \\
\text { Baker } \\
\text { Tillamook } \\
\text { Malheur } \\
\text { Crook } \\
\text { Curry } \\
\text { Lake } \\
\text { Harney } \\
\text { Wallowa } \\
\text { Grant } \\
\text { Sherman } \\
\text { Morrow } \\
\text { Gilliam } \\
\text { Wheeler } \\
\text { Oregon }\end{array}$ & $\begin{array}{r}5354 \\
1236 \\
693 \\
525 \\
510 \\
447 \\
354 \\
231 \\
203 \\
198 \\
187 \\
162 \\
147 \\
126 \\
122 \\
95 \\
95 \\
85 \\
69 \\
54 \\
54 \\
52 \\
47 \\
26 \\
19 \\
17 \\
8 \\
8 \\
7 \\
5 \\
5 \\
2 \\
2 \\
1 \\
0 \\
0 \\
\\
11.146\end{array}$ & $\begin{array}{l}1 \\
2 \\
3 \\
4 \\
5 \\
6 \\
7 \\
8 \\
9 \\
20 \\
11 \\
12 \\
13 \\
14 \\
15 \\
16 \\
17 \\
18 \\
19 \\
20 \\
21 \\
22 \\
23 \\
24 \\
25 \\
26 \\
27 \\
28 \\
29 \\
30 \\
31 \\
32 \\
33 \\
34 \\
35 \\
36\end{array}$ & $\begin{array}{l}\text { Multnomah } \\
\text { Clatsop } \\
\text { Klamath } \\
\text { Jefferson } \\
\text { lane } \\
\text { Jackson } \\
\text { Maricn } \\
\text { Wasco } \\
\text { lood River } \\
\text { Lincoln } \\
\text { Coos } \\
\text { Polk } \\
\text { Umatilla } \\
\text { Josephine } \\
\text { Washington } \\
\text { Benton } \\
\text { Linn } \\
\text { Union } \\
\text { Deschutes } \\
\text { Douglas } \\
\text { Clackamas } \\
\text { Baker } \\
\text { Yamhill } \\
\text { Columbia } \\
\text { Lake } \\
\text { Tillamook } \\
\text { Sherman } \\
\text { Wallowa } \\
\text { Malheur } \\
\text { Crook } \\
\text { Harney } \\
\text { Curri } \\
\text { Grant } \\
\text { Horrow } \\
\text { Gilliam } \\
\text { Wheeler } \\
\text { Oregon }\end{array}$ & $\begin{array}{l}962.9 \\
799.3 \\
671.7 \\
572.1 \\
537.4 \\
485.7 \\
431.5 \\
418.7 \\
400.0 \\
351.9 \\
321.9 \\
319.0 \\
316.8 \\
288.4 \\
287.7 \\
266.0 \\
250.9 \\
258.4 \\
258.2 \\
257.5 \\
240.8 \\
169.9 \\
159.0 \\
155.6 \\
106.5 \\
104.4 \\
94.0 \\
76.7 \\
70.8 \\
70.2 \\
70.2 \\
50.6 \\
27.0 \\
21.8 \\
0.0 \\
0.0 \\
501.0\end{array}$ \\
\hline
\end{tabular}

* Rates per 100,000 population

Multnomah Dounty (excluding Portland)

Portland 4655

410.2

1207.2 


\section{arate op onegon}

MEPORTED GONORRHEA - MUMBER AND PERCENT.

DY SPECIPIC AGE GROUPS.

CALENDAR YEAKS 1961- 1973

\begin{tabular}{|c|c|c|c|c|c|c|c|c|c|c|c|c|c|c|c|c|c|c|c|c|c|c|c|}
\hline$r \leq x$ & $\begin{array}{l}\text { ALL } \\
\text { A GES }\end{array}$ & $\begin{array}{l}\text { UNDE } \\
\text { NO. }\end{array}$ & $!^{10}$ & & & & -19 & No? & & $\begin{array}{l}\text { MINC } \\
\text { No. }\end{array}$ & & $\mathrm{No}^{21}$ & -24 & wo. & -29 & $\begin{array}{r}30 \\
\text { Ho. }\end{array}$ & & $\begin{array}{l}35- \\
\text { Ho. }\end{array}$ & 19 & $\begin{array}{l}10 \\
\text { Nod }\end{array}$ & 1 & Ack & JN KNOU \\
\hline 1964 & 1258 & 6 & .5 & 11 & .9 & 209 & 16.6 & 96 & 7.6 & 322 & 25.6 & 323 & 23.6 & 234 & 28.6 & 133 & 10.6 & 89 & 7.1 & 111 & 9.1 & 43 & 3.4 \\
\hline 1962 & 1287 & 4 & .3 & 4 & .3 & 242 & 16.0 & 107 & 6. 3 & 357 & 27.7 & 342 & 26.6 & 234 & 10.3 & 128 & 9.9 & 84 & 6.5 & 81 & 6.3 & 61 & 4.7 \\
\hline 196 & 1783 & 1 & .0 & 4 & .2 & 234 & 13.1 & 122 & 6.3 & 361 & 20.2 & 560 & 31.4 & 312 & 17.5 & 170 & 9.5 & 87 & 4.9 & 134 & 7.6 & 159 & в. 9 \\
\hline 1964 & 2177 & 6 & .4 & 9 & .4 & 408 & 18.7 & 173 & 0.0 & 590 & 27.5 & 649 & 29.0 & 421 & 19.3 & 217 & 10.0 & 105 & 4.8 & 146 & 6.7 & 41 & 1.9 \\
\hline 1965 & 2520 & 1 & .0 & 7 & .3 & 422 & 16.9 & 207 & o.1 & 637 & 25.3 & 716 & 28.4 & 300 & 19.8 & 255 & 10.1 & 139 & 5.5 & 136 & 5.4 & 137 & 5.5 \\
\hline 1966 & 2611 & a & .3 & 8 & .3 & 528 & 18.7 & 182 & 6.5 & 124 & 25.8 & 804 & 28.6 & 532 & 18.9 & 217 & 7.7 & 139 & 4.9 & 207 & 7.4 & 188 & 6.7 \\
\hline 1967 & 3361 & 13 & .4 & 14 & .4 & 599 & 17.0 & 275 & 0.2 & 901 & 26.8 & 941 & 28. & 600 & 18.1 & 265 & 1.9 & 170 & 5.0 & 200 & 5.9 & 278 & 8.3 \\
\hline 1968 & 4056 & 11 & .3 & 36 & .9 & 828 & 20.4 & 317 & 7.8 & 1192 & 29.4 & 1182 & 29.1 & 710 & 17.6 & 318 & 7.8 & 156 & 3.8 & 197 & 4.9 & 301 & 1.4 \\
\hline 1969 & 5779 & 4 & .1 & 27 &.$s$ & 1323 & 22.9 & 530 & 9.2 & 1804 & 32.7 & 1671 & 28.9 & 1011 & 17.5 & 338 & 5.0 & 195 & 3.4 & 237 & 4.2 & 443 & 7.3 \\
\hline 1970 & 6793 & 9 & .1 & 47 & .7 & 1850 & 27.2 & 634 & 9.3 & 2540 & 37.3 & 2093 & 30.8 & 945 & 13.9 & 604 & 6.0 & $15 \theta$ & 2.3 & 193 & 2.9 & 160 & 6.8 \\
\hline 1971 & 9043 & 15 & .2 & 17 & .8 & 2254 & 25.0 & 046 & 9.0 & 3192 & ${ }^{33} .:^{3}$ & 2895 & 32.0 & 1499 & 17.0 & 498 & 6.0 & 263 & 3.0 & 219 & 2.0 & 175 & 3.0 \\
\hline 1972 & 10206 & 12 & .1 & 82 & .0 & 2652 & 26.0 & 921 & 9.0 & 3667 & 35.9 & 3196 & 31.3 & 1620 & 15.9 & 632 & 6.2 & 247 & 2.4 & 296 & 2.9 & 546 & 5.4 \\
\hline $10 ?:$ & 11.148 & 16 & .1 & 89 & .8 & 2777 & 25.0 & 918 & 8.2 & 3798 & 34.1 & $12^{4}$ & 29.8 & 2046 & 18.7 & 696 & 6.2 & 267 & 2.4 & 207 & 2.6 & 687 & 6.2 \\
\hline
\end{tabular}

- separate total for minors (under aqe 21 ) by present law, 
STATE OF OREGON

REPOIRTED VENEREAL DISEASE

SOURCE OF REPORT

January-December 1973

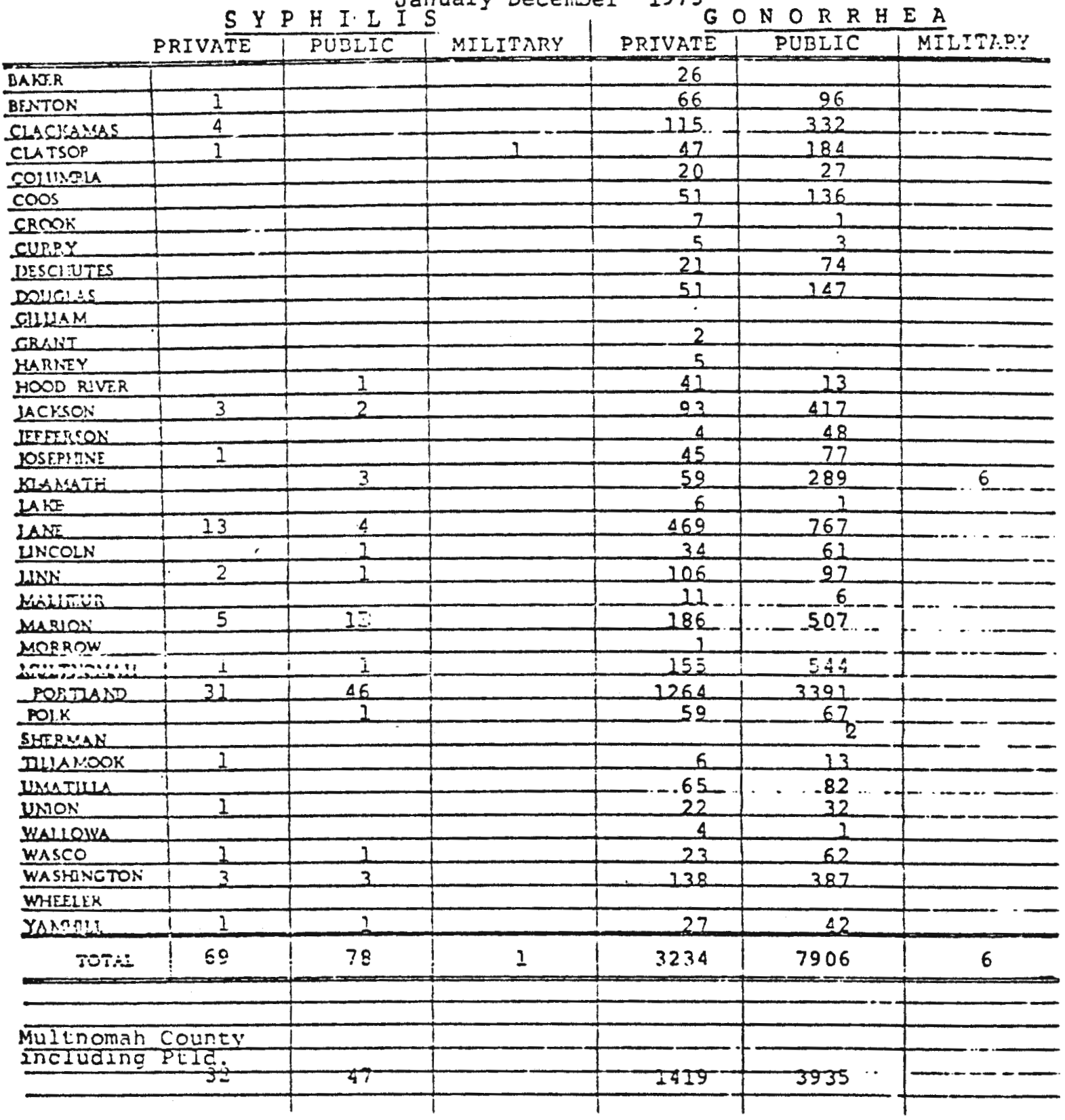




\section{BIBLIOGRAPHY}

Banfield, Edward C. Political Influence. New York: The Free Press, 1961.

Dahl, Robert A. Who Governs? New Haven: Yale University Press, 1961.

Doland, Robert. Dixie City: A Portrait of Political Leadership. Tuscaloosa: University of Alabama Bureau of Public Administration, 1956.

Domhoff, G. William. Who Rules America. Englewood Cliffs, New Jersey: Prentice-Hall, Incorporated, 1967.

Green, Mark J.; Fallows, James M.; Zwick, David R. Who Runs Congress? New York: Bantam Books, 1972.

Hunter, Floyd. Community Power Structure. Chapel Hill, North Carolina: The University of North Carolina Press, 1953.

Jennings, M. Kent. Community Influentials. Iondon: The Free Press of Glencoe, Collier-MacMillan Limited, 1964.

Key, V.O.,Jr. Public Opinion and American Democracy. New York: Alfred A. Knopf, 1965.

Lazarsfield, Paul F. The People's Choice. New York: Lazarsfield and Associates, 1951.

Matthews, Donald R. "The Social Background of Decision Makers." Doubleday Short Stories in Political

Science, pp.20-55. New York: Doubleday and Company, 1954.

Polsby, Nelson $W$. "Three Problems in the Analysis of Community Power." The Sociological Review, vol. XXIV. New York, $19 \overline{59}$.

Ried, Ira. "Ieadership Selections in the Urban Locality Areas." Public Opinion Quarterly, vol. 14, pp. 262284,1950 .

Robinson, James. Congress and Foreign Policy-Making. Homewood: The Dorsey Press, 1962.

Schattschneider, E.E. The Semi-Sovereign People. New York: Holt, Rinehart and Winston, 1960. 
104

Thometz, Carol E. The Decision Makers. Dallas: SMV Press, 1963.

Truman, David. The Government Process. New York, 1951.

Webster's New Collegiate Dictionary. Springfield, Massachusetts: G. \& C. Merriam Company, 1974. 


\section{APPENDIX}

\section{RECOMMENDATIONS OF THE ORIGINAL GOVERNOR'S VENEREAI DISEASE TASK FORCE}

\section{Colinty Health Departments}

It is recommended that County Health Departments:

a. establish an easily accessible venereal disease ciinic open to the public during the evening hours at least one day each week in each county by september 1, 1974; or

b. where it is not feasible to establish such clinics to enter into agreement with existing free or private clinics, private physiciars, hospitals, or other appropriate agencies to serve in such a capacity;

c. disseminate information relating to the location, hours, and telephone numbers of all such venereal disease treatment centers within the county; and

d. establish within such venereal disease clinics procedures which will protect and insure the privacy and dignity of clients and which will increase clients' factual knowledge relating to venereal disease.

\section{Education}

It is recommended that the State Department of Education:

a. present to the Governor by September 1, 1974 a detailed plan for the continued training of elementary and secondary teachers in matters relating to venereal disease education;

b. poll all schools in Oregon by December 31, 1974 to determine the extent to which units of study dealing with verereal disease are being presented in the health education curriculum beginning in the seventin grade;

c. encourage schools not offering such units of study to initiate them immediately;

d. prepare in cooperation with the State Health 
Division a summary statement of the symptoms of syphilis and gonorrhea; the laws relating to the treatment of minors, and the address, hours, and telephone number of venereal disease treatment centers to be distributed to all elementary and secondary school administrators and counselors by September 1, 1974; and,

e. request all community colleges to provide venereal disease diagnosis, treatment, and educational materials free of charge to students by september 1 , 1974.

It is recommended that the Board of High Education:

a. direct all institutions within its jurisdiction to provide venereal disease diagnosis, treatment, and educational materials to students free of charge by september 1, 1974.

It is recommended that all institutions preparing students for health-care professions:

a. submit to the state Health Division by January 1 , 1975 a summary statement of their curriculum as it relates to venereal disease education; and,

b. submit to the State Health Division by January 1, 1975 evidence of actual or planned program improvement in such areas of the curriculum.

3. The Legislative Assembly

It is recommended that the Legislative Assembly:

a. provide the State Health Division with sufficient program improvement funding to support four additional venereal disease epidemiologist staff positions, a toll free telephone number, expansion of the decentralized laboratory program, supportive services, and other venereal disease control programs;

b. provide the Department of Human Resources with program improvement funding at a level necessary to provide one full-time staff position with supporting services and supplies for the oregon Venereal Disease Task Force from July I, 1974 to June 30, 1975:

c. seek additional federal funding for venereal disease control and education programs; and,

d. provide legislation which will free public health 
department records, private physicians' records, and free clinic records as they relate to venereal disease from subpoena powers.

4. Oregon Board of Pharmacy

It is recommended that the Oregon Board of Pharmacy:

a. plan and implement by January 1, 1975 a program of identifying areas of high at-risk population and of encouraging vendors to place condom vending machines in such areas; and,

b. establish a vending license fee not to exceed $\$ 5.00$ per machine for condom vending machines.

5. Oregon Medical Association

It is recommended that the Oregon Medical Association:

a. contact each practicing physician in oregon who might reasonably be expected to diagnose or treat venereal disease in order to solicit support for venereal disease control programs and to provide them with current information concerning incidence trends, new treatment and diagnostic techniques, and other services;

b. initiate an immediate effort among its membership to substantially increase the number of treated cases of venereal disease reported to the state Health Division under the provisions of ORS 434.020;

c. encourage all practicing physicians, free and public clinics, and hospitals to routinely culture for gonorrhea all females between the ages of 12 and 40 years receiving pelvic examinations; and,

d. encourage physicians, students, and parents to include serological tests and cultures for syphilis and gonorrhea in all routine school-related physical examinations.

6. Oregon Venereal Disease Task Force

It is recommended that the oregon Venereal Disease Task Force become an action agency to:

a. plan and implement a continuing program to increase public awareness of venereal disease;

b. assist County Health Departments in improving the organization and management of venereal disease 
clinics, in up-grading the quality of care provided, and in providing facilities which maintain reasonable standards of privacy and dignity for patients;

c. assist communities in establishing Venereal Disease Action Committees (VDAC) to support educational and control efforts in each community; and,

d. encourage pharmacies to display condoms and venereal disease information in such a way that they are readily accessible to all customers.

7. State Health Division

It is recommended that the state Health Division:

a. establish by September 1, 1974 a single, well publicized, toll-free telephone number which physicians, free and public clinics, school personnel, and individual citizens may call to obtain information concerning venereal disease symptoms and treatment, to report cases, or to receive technical assistance;

b. expand the decentralized laboratory program already existing in order to serve private physicians, free and private clinics; and,

c. establish as program improvement four (4) additional field epidemiologist positions in venereal disease control. 
METHODOLOGY

Data utilized in this text has been collected by several methods. The questionnaire had been devisea (see page 87) to obtain individual responses for the members of the Task Force. Interviews with several of the members and staff also provided much of the information used. The medical data relating to the venereal diseases was compiled by Dr. Hugh Tilson, Multnomah County, Oregon Health Officer.

My status with the Task Force was one of participant-observer; thus, day-to-day inter-relationships with the other members provided much of the background for the development of this work.

Numerous works of other authors were also used. The majority of these other works pertained to various influence factors in the community. Additional data concerning special interest groups and various roleplaying of civic-oriented individuals was compiled from the remainder of the sources.

The synthesization of all the materials gathered produced the exploration of the Task Force and the determination of their effectiveness as influential community leaders. 